\title{
Veinticinco años de crisis fiscal en Colombia (1990-2014). Acumulación, confianzay legitimidad en el orden neoliberal*
}

\author{
Twenty five years of fiscal crisis in Colombia \\ (1990-2014). \\ Accumulation, confidence and legitimation in the \\ neoliberal order
}

Andrés Felipe Mora Cortés**

Recibido: 08/11/2014

Aprobado: 06/01/2015

Disponible en línea: 01/05/2015

\begin{abstract}
Resumen
Abstract

A través del cumplimiento de sus funciones de

By the accomplishment of functions of accuacumulación, legitimidad y confianza, la política mulation, legitimation and maintenance of fiscal garantiza la reproducción de las relaciones sociales capitalistas en un contexto de relativa confidence, the fiscal policy guarantees the reproduction of capitalists social relations in a armonía social. Este es el caso en Colombia, context of relative social harmony. This is the donde un análisis histórico permitirá identificar case in Colombia, where an historical analysis la configuración de un Estado bélico-asistencial will allow identifying the configuration of a y de confianza inversionista que, a través de war-assistencialist and confidence State that diferentes mecanismos de represión y contenuses different ways of repression and social ción social garantiza la reproducción del orden containment in order to reproduce the prevailing prevaleciente. En este contexto, se afirmará que order. In this context, the structural origin of the el origen del déficit fiscal tiene una relación difiscal deficit in Colombia has a deep relation with recta con la consolidación del neoliberalismo, la the consolidation of neoliberal order, the persispersistencia del conflicto armado y la expansión tence of the armed conflict and the expansion of
\end{abstract}

doi:10.11144/Javeriana.papo20-1.vacf

* Artículo de reflexión.

** Politólogo y Magíster en Ciencias Económicas de la Universidad Nacional de Colombia. Candidato a PhD en Desarrollo en la Universidad Católica de Lovaina. Docente Asistente del Departamento de Ciencia Política de la Pontificia Universidad Javeriana y de la Universidad Nacional de Colombia, en las áreas de política económica, políticas públicas y política social.

Correo electrónico: moraandres@javeriana.edu.co 
del modelo asistencialista de política social. the assistencialist model of social policy. Only Únicamente transformaciones profundas en deep transformations in those processes would dichos procesos podrán resolver los problemas presupuestales que ha enfrentado el gobierno since 1990. después de 1990.

\section{Palabras Clave:}

política fiscal; acumulación; confianza; legitimidad; Colombia

\section{Cómo citar este artículo:}

Mora, A. (2015). Veinticinco años de crisis fiscal en Colombia (1990-2014).

Acumulación, confianza y legitimidad en el orden neoliberal. Papel Político, 20(1), 6399. http://dx.doi.org/10.11144/Javeriana. papo20-1.vacf

\section{Keywords:}

Fiscal Policy; Accumulation; Confidence; Legitimacy; Colombia 


\section{Introducción}

Más que un modelo económico teóricamente coherente e históricamente estable, el neoliberalismo constituye una lucha por la hegemonía, y es la expresión del reposicionamiento de la clase capitalista financiera durante los últimos cuarenta años. En este sentido, el orden neoliberal es la consecuencia de la voluntad de una clase de propietarios capitalistas de restablecer su ganancia y su poder en un contexto general de retroceso de las luchas sociales y populares. Dicha reafirmación de poder y de intereses se expresa en la relación con los trabajadores, los administradores de las empresas, los responsables de las políticas económicas y sociales en los gobiernos y las instituciones públicas o paraestatales tanto nacionales como internacionales (Duménil y Lévy, 2007).

No obstante, desde el punto de vista de las formaciones sociales concretas, el valor predominante que asume el orden neoliberal debe ser matizado, pues aunque puede ser definido como hegemónico, resulta incorrecto analizarlo sin tener en cuenta las especificidades de los espacios en que se instaura, y las reconfiguraciones que asume en el marco de la dialéctica global-local (Harvey, 2005).

Esta postura es particularmente válida en la comprensión del Estado, pues la tradicional visión dicotómica que ha intentado analizar las relaciones Estado-mercado ha impedido la comprensión del Estado como un agente activo e impulsor de la economía política neoliberal en contextos históricos, sociales y de relaciones de clase específicos. Esta perspectiva evita la caída en argumentos fundamentalmente incorrectos que insisten en la subsunción total del Estado a los intereses del capital financiero multinacional (Panitch, 2000).

Desde esta óptica, el Estado no es observado desde la perspectiva de una entidad que desaparece, sino como un agente que ha redefinido su forma con el fin de responder a las exigencias de la acumulación del capital. Así, en el marco de la emergencia y consolidación del neoliberalismo, el Estado redefine su forma adquiriendo nuevas funciones, coherentes con la reproducción y acumulación de la relación social capitalista (Jessop, 1999). Todo ello, en el marco de relaciones sociales que, si bien, se han sustentado en un relativo repliegue de las luchas sociales y populares, siguen siendo conflictivas y contradictorias. Entendido desde esta perspectiva, el Estado neoliberal y sus políticas serían, entonces, el reflejo de compromisos sociales que regulan los conflictos sin hacerlos desaparecer; es decir, de formas estabilizadas de relaciones de poder. Dichas formas históricas se ubican en medio de las relaciones dialécticas entre lo local-global y lo global-local (Theret, 2000).

Esto es cierto para todos los campos de intervención y acción del Estado. Y en particular para la política fiscal, pues aunque son claras las restricciones y condicionantes que el orden neoliberal impone sobre sus funciones, objetivos e instrumentos, también es claro que:

[...] el papel director del mecanismo de mercado en la determinación del volumen, la composición, los métodos y la distribución de los gastos y los programas del Estado es nulo o 
casi [...]. La administración del Estado en cambio organiza la producción como resultado de un conjunto de decisiones políticas. Estas decisiones políticas se producen dentro de un marco definido de relaciones sociales y como consecuencia de los conflictos sociales, económicos y políticos. (O’Connor, 1994, p. 91)

De esta manera, la condición característica del Estado en el orden neoliberal y el carácter inherentemente conflictivo y político de la política fiscal explican, en el caso colombiano, la crisis que ha caracterizado al presupuesto público durante los últimos veinte años. Entiéndase por crisis el déficit permanente que ha caracterizado a las finanzas públicas del Gobierno nacional central. En efecto, entre 1990 y 2014, el déficit fiscal en Colombia asciende, en promedio, al 3.7\% del PIB. Sin contar privatizaciones, desde el año 1990 y hasta el presente, las finanzas públicas nunca han estado en equilibrio y menos aún han mostrado una situación de superávit ¿Qué explica la recurrente crisis fiscal del Gobierno nacional central?

La respuesta a esta pregunta pasa por reconocer que la política fiscal en Colombia está determinada por el cumplimiento de tres funciones claves: i) acumulación, ii) legitimación y iii) mantenimiento de la confianza. En este marco, la política fiscal ha funcionado como un mecanismo de regulación $n^{1}$ orientado a garantizar la acumulación capitalista neoliberal en un contexto de relativa armonía social. Sin embargo, el cumplimiento de dichas funciones no es complementario; de hecho, lejos de ser compatibles, resultan contradictorias. El resultado de dichas contradicciones es una tendencia marcada por incrementos permanentes en el gasto público. Incrementos que no pueden ser cubiertos

\footnotetext{
${ }^{1}$ Alejada del modelo de equilibrio general walrasiano y del marxismo estructuralista ortodoxo, la teoría de la regulación busca comprender cómo persiste la relación social capitalista a pesar de los elementos críticos y contradictorios que le son inherentes. La teoría de la regulación indaga la manera como se reproduce la estructura determinante de una sociedad en sus leyes generales, analizando los cambios en las relaciones sociales que definen la génesis, desarrollo y decadencia de diversas formas institucionales y las transformaciones sociales que ello implica. Entiende el capitalismo como una totalidad estructurada y dinámica en la cual las luchas políticas y sociales que explican el surgimiento de compromisos institucionales inestables no están sujetas a las dinámicas de acumulación capitalista únicamente. Desde este punto de vista, la regulación puede interpretarse como la primacía relativa de la unidad y la reproducción sobre las luchas y las contradicciones. Es decir, "la regulación es la regulación de la contradicción a través de la contradicción". La teoría de la regulación introduce cuatro categorías esenciales para el análisis de las regularidades de la relación social capitalista en contextos históricos definidos: 1 . El paradigma productivo, 2 . El modo de regulación y, 3 . El régimen de acumulación. Estas tres variables intermedias conforman un modo de desarrollo; es decir, una formación social específica dentro del capitalismo. Finalmente, la teoría de la regulación reconoce que las crisis siempre se hacen presentes en el orden social, político y económico capitalista; por ello, considera la existencia de crisis exógenas, endógenas, de modo de regulación, de régimen de acumulación y de modo de producción. Dichas crisis conllevan a ajustes, cambios o avances hacia otros modos de desarrollo (Boyer, 1992; Jessop, 1999; Neffa, 1998).
} 
por los ingresos del Estado, pues la lógica de explotación tributaria que caracteriza al sistema impositivo del país dificulta recoger un volumen de recursos consistente con el nivel de gasto. En el contexto del orden neoliberal, por lo tanto, el cumplimiento de las funciones anteriormente señaladas explica la configuración en Colombia de un Estado bélico-asistencial y de confianza inversionista en permanente crisis fiscal.

A continuación serán desarrolladas estas afirmaciones. El documento se encuentra compuesto por cuatro apartados. El primero de ellos es esta introducción. En el segundo será presentada la teoría de "la crisis fiscal del Estado". Aquí se resaltarán los progresos interpretativos que esta teoría ofrece en relación con otras teorías convencionales como la teoría neoclásica y la teoría de la elección pública. También serán presentadas las categorías básicas sobre las que se edificará el análisis para el caso colombiano. Seguidamente, en la tercera parte, se presentará un análisis de la política fiscal en Colombia inspirado en las apuestas interpretativas ofrecidas por la teoría de "la crisis fiscal del Estado”. En este punto, se insistirá en la configuración de un Estado bélico-asistencial y de confianza inversionista que, sustentado en lógicas de explotación tributaria, manifiesta su crisis a través del déficit fiscal que siempre lo ha acompañado. Finalmente, se presentan algunas conclusiones.

\section{La crisis fiscal del Estado: acumulación, confianza y legitimidad}

Tradicionalmente, en los libros de texto se han priorizado visiones voluntaristas y positivas sobre la comprensión de la política económica que remiten directamente a un debate sobre objetivos e instrumentos. Siguiendo a Etienne Kirschen, por ejemplo, Juan R. Cuadrado considera que "los términos política económica describen el proceso mediante el cual el gobierno, a la luz de fines políticos más generales, decide sobre la importancia relativa de ciertos objetivos, y en cuanto considera necesario utiliza instrumentos o cambios institucionales con la intención de lograr tales objetivos" (Cuadrado, 1997, p. 146). Esta visión voluntarista toma su expresión más radical cuando en los modelos neoclásicos se asume la existencia de un “dictador benévolo”, capaz de maximizar funciones de bienestar social, sujeto a cierto tipo de restricciones intertemporales o de política.

La racionalidad extrema que esta postura otorga a las decisiones de política económica en general, y de política fiscal en particular, ha sido objeto de duras críticas, todas ellas provenientes de diversas ramas de la economía política. Desde las lecturas de la elección pública, por ejemplo, se ha insistido en que el presupuesto público es el resultado de la interacción entre diversos grupos de la sociedad con intereses diversos y en competencia. Esta situación conlleva a que los supuestos objetivos generales que buscaría materializar la política fiscal sean desvirtuados y se asista, por el contrario, a que el Estado se comprometa con cierto tipo de facciones sociales que al captar rentas particulares, sobreexplotan el presupuesto público. El resultado es una tendencia 
clara hacia un mayor déficit fiscal y hacia incrementos continuos en el nivel de deuda pública. La denominada "tragedia de los comunes" se hace evidente, pues cada grupo social, aunque percibe los beneficios de explotar la política fiscal a su favor, no enfrenta directamente los costos asociados con dicha explotación, pues puede diferirlos intergeneracionalmente a través del endeudamiento provocado por el déficit.

Las restricciones de política enfrentadas por el supuesto dictador benévolo son ineludibles: "El problema es que las reglas de juego son tales que la prudencia y responsabilidad fiscales se encuentran más allá de los límites de lo políticamente razonable. Los contribuyentes disfrutan los beneficios del gasto público; no disfrutan con el pago de impuestos. La política del déficit es tan sencilla como esto” (Buchanan, 1984, p. 7). La solución a los problemas de sobreexplotación del presupuesto pasaría por la definición de arreglos institucionales cooperativos que eviten la "tragedia de los comunes" a través de la internacionalización de los costos por parte de cada uno de los grupos que capturan rentas (Echeverry et al., 2004).

No obstante, la teoría de la elección pública sigue siendo estrecha debido a que concibe las instituciones únicamente como instrumentos destinados a la corrección de los problemas de coordinación. En efecto, en el marco de la elección pública, los asuntos fiscales se siguen concibiendo como un problema de economía política en el que se distribuyen de un determinado modo recursos insuficientes entre demandas casi insaciables y en competencia. De esta manera, se sustituye el análisis crítico del Estado y del presupuesto por una aceptación implícita del equilibrio subóptimo existente entre diversos intereses estratégicos privados.

¿Cómo producir, entonces, un análisis crítico de la política fiscal? Para avanzar en este camino se considera que son necesarias dos condiciones: i) Interpretar las políticas y las instituciones como el reflejo de compromisos sociales que regulan los conflictos sin hacerlos desaparecer y, ii) Entender que una vez realizados, dichos compromisos crean reglas y regularidades en la evolución de los gastos e ingresos públicos (Boyer, 1992). La traducción de estas apuestas teóricas al campo de la política fiscal es claro: el volumen y la composición del gasto así como la distribución de las cargas fiscales están determinados por "conflictos y compromisos sociales institucionalizados" en el marco de condiciones estructurales contradictorias ${ }^{2}$.

\footnotetext{
2 ¿Qué es un compromiso institucionalizado? "En el origen del compromiso nos encontramos con una situación de tensión y conflicto entre grupos socioeconómicos. El enfrentamiento cambia según los intereses en juego. En la medida en que ninguna de las fuerzas es capaz de dominar a sus adversarios al punto de poder imponer totalmente sus intereses, surge la necesidad de realizar un compromiso. Los compromisos institucionales se diferencian de la institucionalización autoritaria del orden público. La institucionalización se refiere a la puesta en marcha de una forma de organización que crea reglas, derechos y obligaciones para las partes involucradas, imponiendo
} 
Bajo estos presupuestos, y si se asume el capital como una relación social inherentemente crítica y conflictiva, la política fiscal se comprendería no como una estrategia voluntarista destinada a la maximización del bienestar social, sino como el conjunto de decisiones y acciones destinadas a gestionar los conflictos y contradicciones de la sociedad: "ni el volumen y la composición del gasto del Gobierno ni la distribución de las cargas fiscales están determinados por las leyes del mercado, sino que reflejan los conflictos sociales y económicos entre grupos y clases y están estructuralmente determinados por ellos" (O’Connor, 1994, p. 21).

Es esta la denominada teoría de la "crisis fiscal del Estado". Esta perspectiva concibe el Estado moderno como un objeto del conflicto de clases, y entiende la crisis fiscal del Estado -es decir, el inevitable desajuste estructural entre los gastos y los ingresos estatales- como producto de la extensión de la "contradicción fundamental" del capital al campo fiscal, y de la manera como dicha contradicción se regula a través del cumplimiento de dos funciones básicas: las funciones de acumulación y legitimación. Esto en un contexto en que los costes de la política fiscal se socializan mientras que sus beneficios se concentran. Es en este marco en que:

El Estado capitalista debe tratar de satisfacer dos funciones básicas y a menudo contradictorias: acumulación y legitimización. Esto significa que el Estado debe intentar mantener o crear condiciones en las cuales sea posible la acumulación rentable del capital. Además, el Estado debe tratar también de mantener o crear condiciones necesarias a la armonía social. (O'Connor, 1994, p. 26)

Así, la política fiscal actúa como una modalidad de regulación de las tensiones y conflictos económicos, sociales y políticos. Los límites y naturaleza de la política fiscal reflejan, entonces, la intensidad o agudización de las contradicciones del modo de producción capitalista y la manera como dichas tensiones se regulan para garantizar la reproducción de las relaciones sociales que le dan forma histórica concreta. El sentido positivo y voluntarista ofrecido por las lecturas concentradas en los objetivos e instrumentos del presupuesto público, y los aportes de la teoría de la elección pública en torno

una disciplina con respecto a la institución, fijando así un modo de comportamiento para cada actor, grupo o individuo, frente al cual adaptan progresivamente sus comportamientos y estrategias. Uno de los resultados de los compromisos institucionales para resaltar, es la robustez de las construcciones creadas en sus aspectos fundamentales. Los compromisos institucionales se constituyen en un entorno que sirve de guía para que la población y los grupos involucrados fijen sus comportamientos. No es sorprendente entonces que, esa rigidez en las posiciones e intereses adquiridos en el marco de los compromisos institucionales sea objeto de crecientes tensiones con el paso del tiempo" (Misas, 2002, p. 310). 
a la tragedia de los comunes, son superados por una visión de economía política más amplia que establece vínculos directos entre la política fiscal, el modo de producción capitalista y las contradicciones y conflictos que le son inherentes.

Bajo estas coordenadas, las funciones de acumulación y legitimación del Estado implican un aumento permanente del gasto estatal, que no es susceptible de ser cubierto por los recursos provenientes de una mayor explotación tributaria ${ }^{3}$. La contradicción consiste fundamentalmente en que la garantía de la función de acumulación (a través de mayores niveles de gasto en capital físico, capital humano e inversiones en ciencia, tecnología e innovación) implica que las consecuencias propias del capitalismo en cuanto a desigualdad, pobreza, desempleo, subdesarrollo regional, desindustrialización y quiebras industriales tienden a profundizarse, obligando a aumentos importantes en gastos de legitimación. Resumiendo: el mayor nivel de gasto público en acumulación implica aumentos considerables de gasto destinados a garantizar una relativa armonía social. La trayectoria ascendente de este conjunto de gastos no puede ser cubierta por los recursos provenientes de las lógicas de explotación tributaria que a su vez, explican la necesidad de mayores gastos en asistencia pública. El resultado: un déficit estructural explicado por los elementos inherentemente críticos del capitalismo, y por las correlaciones de fuerza y conflicto que se tejen en sus entrañas.

La tabla 1 resume los componentes de la crisis fiscal del Estado e incorpora otro componente fundamental para la comprensión del proceso en las economías del Sur: la garantía de confianza inversionista en el contexto de la financiarización y las necesidades recurrentes de endeudamiento. Los dispositivos de regulación económica y social en las economías del Sur no pueden verse por fuera de las presiones e influencias que sobre ellas ejerce la economía-mundo (Brenner, 1997). Por supuesto, esto no implica que el capitalismo financiero "sobredetermine" las dinámicas de la política fiscal en las economías del Sur. Por el contrario, es la relación triangular recíproca que se establece entre las funciones de acumulación, legitimación y confianza en donde pueden encontrarse las claves para comprender el porqué de la persistencia del déficit fiscal.

$¿$ La crisis fiscal de los últimos veinticinco años puede ser comprendida bajo estas coordenadas teóricas? Primeramente, hay que señalar que, tal y como lo demuestra la figura 1, los ingresos del Gobierno nacional central siempre han sido inferiores a sus

\footnotetext{
3 "El presupuesto estatal puede ser considerado como un complejo mecanismo cuya finalidad es redistribuir la renta hacia delante y hacia atrás dentro de la clase trabajadora [...]. La financiación mediante impuestos es -y ha sido siempre- una forma de explotación económica y, por consiguiente, uno de los objetos del análisis de clases [...] toda modificación importante en el equilibrio de las fuerzas políticas y de clase queda reflejada en la estructura tributaria. Dicho de otro modo, los sistemas fiscales no son más que las formas concretas que adoptan los distintos sistemas de clase" (O'Connor, 1994, p. 249).
} 
gastos, lo cual ha llevado a un déficit recurrente que, a su vez, explica la mayor necesidad de recursos de financiamiento interno y externo. En promedio, entre los años 1990 y 2014, los ingresos totales del Gobierno nacional central ascienden al 81\% de los gastos totales. Esta situación explica por qué, en promedio, durante los últimos veinte años, el déficit fiscal -sin contar los recursos de privatizaciones- se ha mantenido en niveles cercanos al 3,7\% del PIB, mostrando un deterioro continuo entre los años 1990 y 2000 (cuando asciende al 5.27\% del PIB), recuperándose hasta el año 2008 cuando alcanzó el 1.77\% del PIB, y exhibiendo un nuevo deterioro hasta alcanzar el 3.8\% en 2009 (figura 2).

\section{Tabla 1. Crisis fiscal del Estado}

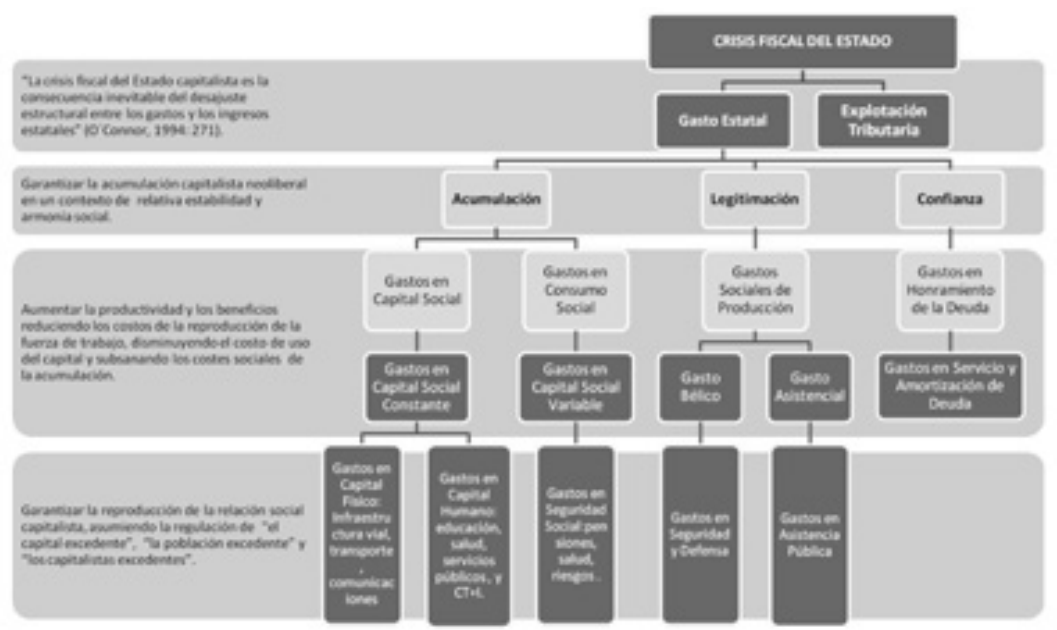

Fuente: elaboración propia con base en O'Connor (1994); Brenner y Glick (1997).

Figura 1

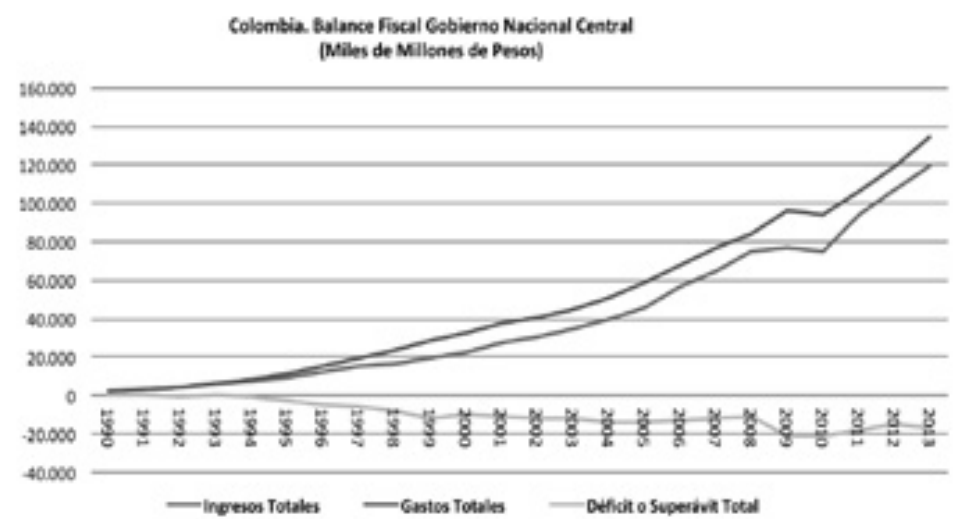

Fuente: Ministerio de Hacienda y Crédito Público. Cálculos propios. 


\section{Figura 2}

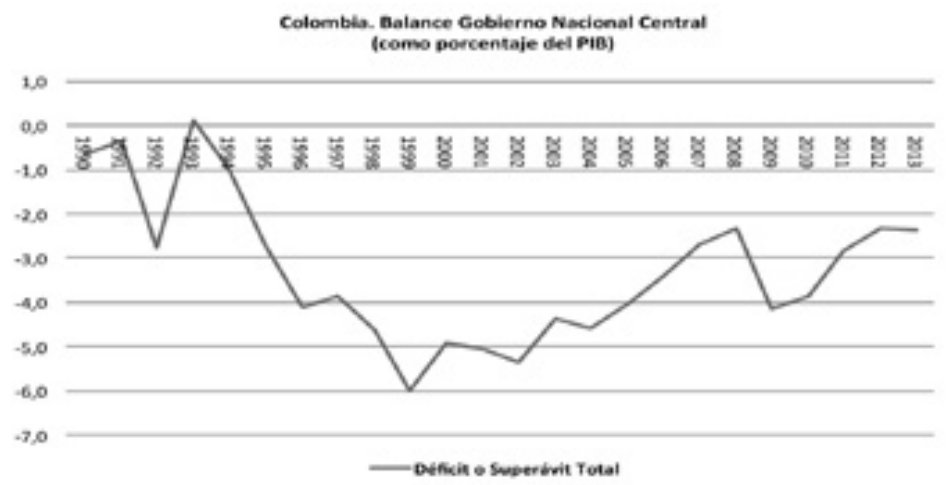

Fuente: Ministerio de Hacienda y Crédito Público

Más allá de explicaciones asociadas a los fallos del mercado, a la captura de rentas por parte de determinados grupos de presión, o al comportamiento oportunista de las autoridades fiscales, es necesario ubicar la discusión en el campo de las contradicciones inherentes al modo de producción capitalista. Tal y como se sostendrá en la tercera sección del documento, el mencionado déficit estructural colombiano es producto de las lógicas de regulación adelantadas por el Estado bajo el cumplimiento de las funciones de acumulación, legitimación y confianza. Este proceso ha llevado a la configuración de un Estado bélico-asistencial y de confianza inversionista que, bajo la profundización de lógicas de explotación tributaria, resulta incapaz de resolver sus problemas fiscales. Como se observará, esta es la consecuencia de la intersección de aspectos globales y locales relativos a la consolidación del orden neoliberal, el sostenimiento del conflicto interno armado y la desigualdad profunda que ha caracterizado históricamente al país. Neoliberalismo, conflicto interno armado y desigualdad social: son estos los orígenes políticos del déficit estructural en el marco de la búsqueda contradictoria de objetivos de acumulación, confianza y legitimidad.

\section{Colombia: explotación tributaria, Estado bélico-asistencial y confianza inversionista}

Generalmente, el problema del déficit fiscal en Colombia ha sido asumido desde una perspectiva de inflexibilidades de gasto y bajo recaudo tributario. Las reformas se han orientado, entonces, a remover aquellas fuentes constitucionales, legales y políticas de inflexibilidad y a presentar sucesivas reformas tributarias que al comienzo se pretenden estructurales pero que, después del debate político y bajo ciertas correlaciones de fuerza, terminan siendo coyunturales e insuficientes para alcanzar el anhelado equilibrio presupuestal (Junguito y Rincón, 2004). 
Sin embargo, el déficit fiscal no es únicamente el producto de relaciones de fuerza entre grupos sociales en competencia por la captura de recursos. Es principalmente, el reflejo de aspectos estructurales que trascienden el poder de las autoridades económicas para emprender el ajuste y para los cuales las reformas institucionales destinadas a minimizar las inflexibilidades son totalmente insuficientes. El voluntarismo no es el patrón dominante en la definición del presupuesto público. Este es el reflejo de la manera como la política fiscal cumple sus funciones reguladoras de acumulación, legitimación y confianza en un contexto de relaciones dialécticas entre lo global y lo local. En Colombia dichas funciones se han materializado en los incrementos en el gasto en infraestructura, capital humano y ciencia, tecnología e innovación (para el caso de la función de acumulación), en el aumento de los gastos sociales y de seguridad y defensa para garantizar la función de legitimación, y en el incremento sostenido en los gastos correspondientes al servicio de deuda para brindar confianza inversionista. Ello, en un escenario en que los ingresos provenientes de la mayor explotación tributaria resultan insuficientes en tanto privilegian la tributación indirecta sobre las mayores cargas impositivas al capital y la riqueza.

Por lo tanto, y contrario a lo que sostienen los analistas de las inflexibilidades del presupuesto, no existe un patrón absoluto del tamaño que deba tener el Estado. El Estado y sus finanzas son reflejo de correlaciones de fuerza y de los mecanismos de regulación requeridos para enfrentar los elementos inherentemente críticos de la relación social capitalista. En este sentido, condiciones globales asociadas con la hegemonía neoliberal se intersectan con elementos particulares relativos al conflicto interno armado y a los niveles históricos de desigualdad y pobreza que ha mostrado el país. Es en esta intersección en que debe encontrarse el origen de la crisis fiscal del Estado y la consiguiente configuración de un Estado bélico-asistencial y de confianza inversionista que bajo diversos dispositivos de represión y contención social intenta recrear las condiciones de estabilidad requeridas para la reproducción de la relación social capitalista, a través de un mayor déficit fiscal. A continuación serán desarrolladas estas ideas.

\section{Explotación tributaria: los impuestos indirectos y el impacto neutral de la estructura impositiva sobre la desigualdad}

Durante la década de 1990 la consecución del saneamiento fiscal constituía un elemento imprescindible para el logro eficiente de los objetivos de apertura comercial, la eliminación del control de precios y la materialización de los objetivos de desreglamentación y privatización que se implementaban en el marco del modelo neoliberal. Por ello, las concesiones fiscales otorgadas al orden que se consolidaba -como la reducción a los impuestos directos a las exportaciones, la liberalización y la desgravación de las importaciones y los impuestos sobre el capital financiero- significaron fuertes presiones fiscales en el corto plazo. Esta situación obligó a los gobiernos a definir medidas compensatorias 
como el aumento y consolidación del IVA y el impuesto sobre la renta. A estos esfuerzos se unieron otros ingresos transitorios relacionados con los procesos de privatización y el estímulo al esfuerzo fiscal propio de las entidades territoriales (Perry y Herrera, 1994).

Es este el origen de una mayor explotación tributaria en América Latina, pues las estructuras tributarias se ajustaban en función de las necesidades del capital, omitiendo sus objetivos de equidad y mayor progresividad. Desde el neoliberalismo se ha insistido en los efectos negativos que sobre el crecimiento económico y sobre el recaudo generan las tasas impositivas elevadas y diferenciadas en términos del nivel de ingresos de los agentes. Se considera, entonces, la necesidad de evitar los impuestos sobre los ingresos y la riqueza, establecer modelos impositivos planos que no afecten negativamente los precios relativos de los bienes y aumentar la eficiencia en el recaudo a través de impuestos fácilmente controlados por las autoridades fiscales (Giraldo, 2001). Esta ha sido la inspiración básica de las reformas fiscales promovidas en América Latina en las últimas dos décadas, y Colombia no ha sido la excepción:

Entre 1990 y 2003 se aprobaron ocho reformas tributarias, contando la creación del impuesto de seguridad democrática en 2002. En promedio se aprobó una reforma cada 15 meses, lo cual además del desgaste administrativo y de la carga sobre la gestión legislativa que ha implicado, muestra la gran inestabilidad de las reglas de juego impositivas en el país. Además, revela el carácter coyuntural de las reformas sin que se haya abocado una reforma estructural para corregir problemas graves en la estructura de impuestos que han llevado a la reproducción de profundas inequidades, la proliferación de exclusiones y exenciones y la falta de transparencia proclive a elevados niveles de evasión y elusión tributarias [...]. La estructura del IVA, como resultado de las sucesivas reformas tributarias, ha pasado de una progresividad moderada a una relativa neutralidad, e incluso a una regresividad en el caso de los alimentos. (Betancourt, 2005, p. 385)

El efecto perverso de este tipo de medidas puede observarse en los efectos redistributivos que generan. En el caso de América Latina, Servén (2008) demuestra que la estructura tributaria tiene una incidencia neutral en términos del avance hacia sociedades con mejores niveles de distribución del ingreso. Al simular el coeficiente de Gini, antes y después de la política fiscal, Servén concluye que en Europa el Gini asciende a 0.46 antes de la política fiscal y se reduce al 0.31 después de la política fiscal. Específicamente para América Latina, el coeficiente de Gini antes de la política fiscal asciende a 0.52 y después de la misma se mantiene en 0.50. Para Colombia, las virtudes redistributivas de la política fiscal son prácticamente inexistentes: el coeficiente de Gini antes de la política fiscal asciende a 0.56, después es de 0.53. La persistencia de la desigualdad constituye un efecto directo del mantenimiento de lógicas de explotación tributaria. 
Por su parte, Ocampo y Malagón (2012) demuestran que la mayor parte del muy bajo efecto redistributivo de la política fiscal se encuentra en el componente del gasto público. Así, en comparación con lo observado en los países de la Organización para la Cooperación y el Desarrollo Económico (OCDE), las posibilidades de mejoramiento del potencial redistributivo de la política tributaria es amplio, pues en esos países el $24 \%$ de la redistribución total efectuada desde la política fiscal es debida a la política tributaria. En América Latina, en contraste, este porcentaje alcanza únicamente el 11\% (tabla 2).

\section{Tabla 2}

\section{Efecto redistributivo de la política fiscal: Coeficiente de Gini} del ingreso antes y después de impuestos y transferencias

\begin{tabular}{|c|c|c|c|c|c|c|c|}
\hline \multirow[b]{2}{*}{ País } & \multicolumn{2}{|c|}{ Coeficiente de Gini } & \multicolumn{3}{|c|}{ Redistribución de la Política Fiscal } & \multicolumn{2}{|c|}{ \% de la Distribución } \\
\hline & $\begin{array}{l}\text { Ingreso antes } \\
\text { de impuestos y } \\
\text { transferencias }\end{array}$ & $\begin{array}{c}\text { Ingreso } \\
\text { después de } \\
\text { impuestos y } \\
\text { transferencias }\end{array}$ & Total & Impuestos & Transferencias & Impuestos & Transferencias \\
\hline Argentina & 0,500 & 0,481 & 0,019 & 0,005 & 0,014 & $26 \%$ & $74 \%$ \\
\hline Bolivia & 0,604 & 0,543 & 0,061 & 0,000 & 0,061 & $0 \%$ & $100 \%$ \\
\hline Brasil & 0,560 & 0,543 & 0,017 & $-0,001$ & 0,018 & $-6 \%$ & $106 \%$ \\
\hline Chile & 0,472 & 0,456 & 0,016 & 0,002 & 0,014 & $13 \%$ & $88 \%$ \\
\hline Colombia & 0,568 & 0,522 & 0,046 & 0,012 & 0,034 & $26 \%$ & $74 \%$ \\
\hline Costa Rica & 0,451 & 0,383 & 0,068 & 0,008 & 0,060 & $12 \%$ & $88 \%$ \\
\hline El Salvador & 0,474 & 0,458 & 0,016 & $-0,020$ & 0,036 & $-125 \%$ & $225 \%$ \\
\hline Guatemala & 0,463 & 0,426 & 0,037 & 0,006 & 0,031 & $16 \%$ & $84 \%$ \\
\hline Honduras & 0,535 & 0,481 & 0,054 & $-0,001$ & 0,055 & $-2 \%$ & $102 \%$ \\
\hline México & 0,510 & 0,494 & 0,016 & 0,009 & 0,007 & $56 \%$ & $44 \%$ \\
\hline Nicaragua & 0,531 & 0,470 & 0,061 & 0,001 & 0,060 & $2 \%$ & $98 \%$ \\
\hline Panamá & 0,538 & 0,458 & 0,080 & 0,006 & 0,074 & $8 \%$ & $93 \%$ \\
\hline Perú & 0,486 & 0,479 & 0,007 & 0,008 & $-0,001$ & $114 \%$ & $-14 \%$ \\
\hline $\begin{array}{l}\text { Promedio } \\
\mathrm{AL}\end{array}$ & 0,515 & 0,476 & 0,038 & 0,003 & 0,036 & $11 \%$ & $89 \%$ \\
\hline $\begin{array}{l}\text { Promedio } \\
\text { OCDE }\end{array}$ & 0,450 & 0,284 & 0,166 & 0,040 & 0,126 & $24 \%$ & $76 \%$ \\
\hline
\end{tabular}

Fuente: Ocampo y Malagón (2012)

En este contexto, los efectos redistributivos de los impuestos directos e indirectos se anulan mutuamente en Colombia, y las transferencias monetarias no tienen impacto alguno sobre el coeficiente de Gini. Diversos análisis revelan que los impuestos directos reducen el coeficiente de Gini en un punto porcentual, mientras que los impuestos indirectos lo aumentan en la misma proporción, dando como resultado un impacto global neutro del sistema tributario. De hecho, los impuestos al valor agregado equivalen a cerca de la mitad de los ingresos de los hogares en el decil más pobre (que tienen ingresos monetarios muy bajos), pero representan solamente el 5.6\% de los ingresos del decil más rico (Moller, 2013).

En consecuencia, se ha demostrado que en América Latina (incluida Colombia) el potencial para edificar una política fiscal más progresiva y redistributiva se haya en las 
variaciones sobre el impuesto a la renta. En efecto, el impuesto sobre la renta, que incluye personas físicas y sociedades, resulta ser el más progresivo y además produce una mejora en la redistribución. Mientras tanto, el resto de tributos resultan ser regresivos y empeoran la distribución, siendo los de regresividad más significativa los impuestos selectivos sobre el consumo (bebidas alcohólicas, cervezas, tabacos). Así, en América Latina el sistema tributario en su conjunto resulta ser regresivo y empeora la distribución (tabla 3).

Tabla 3

Índices de concentración para el promedio de países de América Latina (Deciles de hogares por ingreso familiar equivalente)

\begin{tabular}{|l|l|l|l|l|l|}
\hline \multirow{2}{*}{\multicolumn{2}{|c|}{ Impuestos }} & \multicolumn{5}{c|}{ Índices } \\
\cline { 2 - 7 } & $\begin{array}{c}\text { Gini antes de } \\
\text { impuestos }\end{array}$ & $\begin{array}{c}\text { Concentración } \\
\text { de impuestos }\end{array}$ & $\begin{array}{c}\text { Kakwani } \\
\text { (Progresividad)* }\end{array}$ & $\begin{array}{c}\text { Gini post- } \\
\text { impuestos }\end{array}$ & $\begin{array}{c}\text { Reynods-Smolesnsky } \\
\text { (Redistribución)** }\end{array}$ \\
\hline Impuestos sobre la renta & 0,564 & 0,672 & 0,108 & 0,561 & $-0,003$ \\
\hline Patrimonio & 0,564 & 0,461 & $-0,103$ & 0,564 & 0,000 \\
\hline General sobre consumos & 0,564 & 0,475 & $-0,089$ & 0,567 & 0,003 \\
\hline Selectivos sobre consumos & 0,564 & 0,387 & $-0,177$ & 0,567 & 0,003 \\
\hline Comercio exterior & 0,564 & 0,454 & $-0,11$ & 0,566 & 0,002 \\
\hline Seguridad social & 0,564 & 0,487 & $-0,077$ & 0,565 & 0,001 \\
\hline Total Sistema Impositivo & 0,564 & 0,497 & $-0,067$ & 0,574 & 0,010 \\
\hline
\end{tabular}

Fuente: Jiménez y Ruiz (2009)

NOTAS:

* Índice de Kakwani: existe mayor progresividad si el impuesto se concentra más en los agentes económicos con mayor ingreso y/o riqueza. En este sentido, el índice tenderá a estar por encima de cero (0). Si el índice se ubica por debajo de cero (0), se considera que el impuesto en cuestión es regresivo.

** Índice de Reynods-Smolensky: considera que el impuesto redistribuye más si la diferencia entre el Gini antes de impuestos y el Gini post-impuestos es mayor y negativa. Si la diferencia es baja, el impuesto redistribuye menos. Y si la diferencia es positiva el impuesto es regresivo.

Esta situación se explica por los cambios de la estructura tributaria en las últimas décadas, caracterizada fundamentalmente por el marchitamiento de los impuestos al comercio exterior, el bajo incremento del impuesto a la renta y la propiedad, la disminución del recaudo vinculado a la seguridad social y el fuerte dinamismo del IVA. Situación contraria a la observada en la OCDE, donde el impuesto a la renta y la propiedad explican más del 40\% de los ingresos tributarios totales (tabla 4 y figura 3 ).

\section{Tabla 4}

\section{Comparación de la estructura tributaria} entre América Latina y la OCDE

\begin{tabular}{|l|l|r|}
\cline { 2 - 3 } \multicolumn{1}{c|}{} & \multicolumn{2}{c|}{ América Latina } \\
\cline { 2 - 3 } \multicolumn{1}{c|}{} & $\mathbf{1 9 9 0}$ & $\mathbf{2 0 0 8}$ \\
\hline Renta más propiedad & $24,90 \%$ & $29,80 \%$ \\
\hline IVA & $24,40 \%$ & $36,20 \%$ \\
\hline $\begin{array}{l}\text { Específicos a bienes y } \\
\text { servicios y Otros impuestos }\end{array}$ & $20 \%$ & $12,10 \%$ \\
\hline
\end{tabular}

\begin{tabular}{|l|c|c|}
\cline { 2 - 3 } \multicolumn{1}{c|}{} & \multicolumn{2}{c|}{ OCDE } \\
\cline { 2 - 3 } \multicolumn{1}{c|}{} & $\mathbf{1 9 9 0}$ & $\mathbf{2 0 0 8}$ \\
\hline Renta más propiedad & $44,80 \%$ & $42,40 \%$ \\
\hline IVA & $17,30 \%$ & $18,90 \%$ \\
\hline $\begin{array}{l}\text { Específicos a bienes y } \\
\text { servicios y Otros impuestos }\end{array}$ & $13,70 \%$ & $12,20 \%$ \\
\hline
\end{tabular}




\begin{tabular}{|l|l|l|}
\cline { 2 - 3 } \multicolumn{1}{c|}{} & \multicolumn{2}{c|}{ América Latina } \\
\cline { 2 - 3 } \multicolumn{1}{c|}{} & $\mathbf{1 9 9 0}$ & $\mathbf{2 0 0 8}$ \\
\hline Comercio exterior & $13,70 \%$ & $7,70 \%$ \\
\hline Seguridad social & $17 \%$ & $14,30 \%$ \\
\hline
\end{tabular}

\begin{tabular}{|l|l|l|}
\cline { 2 - 3 } \multicolumn{1}{c|}{} & \multicolumn{2}{c|}{ OCDE } \\
\cline { 2 - 3 } \multicolumn{1}{c|}{} & $\mathbf{1 9 9 0}$ & $\mathbf{2 0 0 8}$ \\
\hline Otros impuestos & $1,10 \%$ & $0,70 \%$ \\
\hline Seguridad social & $23,10 \%$ & $25,50 \%$ \\
\hline
\end{tabular}

Fuente: Jiménez y Ruiz (2009)

\section{Figura 3. Comparación de la estructura tributaria entre América Latina y la OCDE}

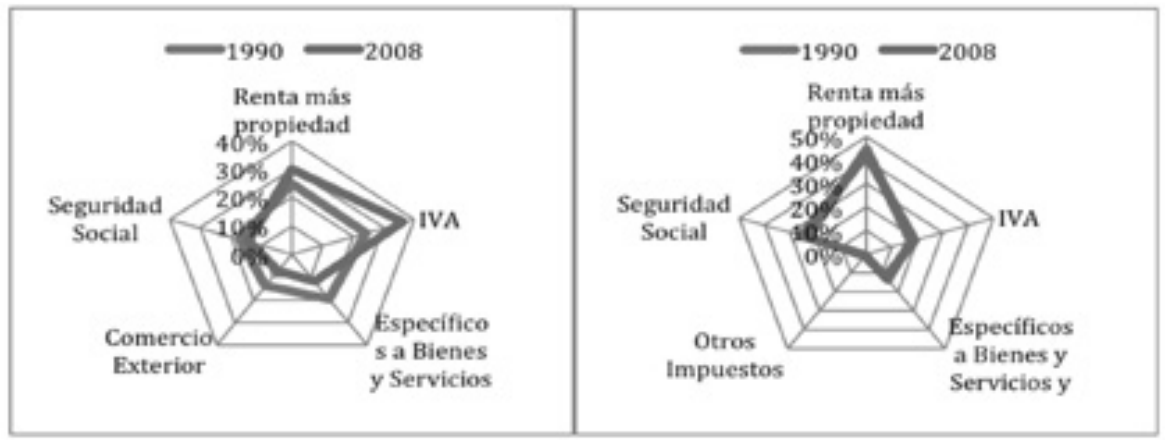

Fuente: Jiménez y Ruiz (2009)

A esta situación debe sumarse que la presión tributaria en América Latina (es decir, el total de ingresos tributarios como porcentaje del PIB) no ha representado mayores incrementos, y ha pasado del $13.3 \%$ al $17.6 \%$ del PIB, lo cual resulta bastante modesto si se compara con lo observado en otras regiones. En el caso de Colombia, la presión tributaria asciende al 15,6\% del PIB, por debajo de países como Brasil, Argentina, Uruguay, Costa Rica, Nicaragua, Bolivia, Honduras, Perú, Honduras, Ecuador y Costa Rica. Del total de 19 países de América Latina y el Caribe, la presión tributaria de Colombia, únicamente se encuentra por encima de la de República Dominicana, El Salvador, Venezuela, Paraguay, Guatemala, Haití y México. Países como Dinamarca, Suecia y Noruega muestran un nivel de presión tributaria cercana al 47\% del PIB (tabla 5).

\section{Tabla 5}

Variación en la presión tributaria en América Latina (\% del PIB)

\begin{tabular}{|l|l|l|l|l|}
\hline \multicolumn{1}{|c|}{ Tipo de impuesto } & $\mathbf{1 9 9 0 - 1 9 9 2}$ & $\mathbf{2 0 0 5 - 2 0 0 8}$ & $\begin{array}{l}\text { Variación } \\
\text { absoluta }\end{array}$ & $\begin{array}{c}\text { Participación } \\
\text { en la variación }\end{array}$ \\
\hline Renta & 2,9 & 4,5 & 1,6 & 37,2 \\
\hline Propiedad & 0,4 & 0,7 & 0,3 & 7,0 \\
\hline $\begin{array}{l}\text { IVA (General sobre otros } \\
\text { bienes y servicios) }\end{array}$ & 3,3 & 6,4 & 3,1 & 72,1 \\
\hline $\begin{array}{l}\text { Específicos a bienes y } \\
\text { servicios }\end{array}$ & 1,9 & 1,7 & $-0,2$ & $-4,7$ \\
\hline
\end{tabular}




\begin{tabular}{|l|l|l|l|l|}
\hline Comercio exterior & 1,8 & 1,4 & $-0,4$ & $-9,3$ \\
\hline Otros impuestos & 0,7 & 0,4 & $-0,3$ & $-7,0$ \\
\hline Seguridad social & 2,3 & 2,5 & 0,2 & 4,7 \\
\hline Total ingresos tributarios & 13,3 & 17,6 & 4,3 & 100,0 \\
\hline
\end{tabular}

Fuente: Jiménez y Ruiz (2009)

Finalmente, el gasto tributario, es decir, la diferencia entre los tipos impositivos nominales y los impuestos reales que terminan pagando los contribuyentes por cuenta de incentivos y estímulos fiscales, es bastante costoso y alcanza un promedio del $4.45 \%$ del PIB en América Latina. Sobresale aquí, el mayor nivel de gasto tributario relacionado con los impuestos sobre la renta personal (aunque Colombia es la excepción) (tabla 6).

Tabla 6

Estimaciones del gasto tributario como porcentaje del PIB

\begin{tabular}{|l|l|l|l|l|l|}
\hline País & $\begin{array}{c}\text { Impuestos } \\
\text { directos } \\
\text { (\% PIB) }\end{array}$ & $\begin{array}{c}\text { Impuestos sobre } \\
\text { la renta de las } \\
\text { empresas (\% PIB) }\end{array}$ & $\begin{array}{c}\text { Impuestos sobre } \\
\text { la renta personal } \\
\text { (\% PIB) }\end{array}$ & $\begin{array}{c}\text { Impuestos } \\
\text { Indirectos } \\
\text { (\% PIB) }\end{array}$ & $\begin{array}{c}\text { Total } \\
(\% \text { PIB) }\end{array}$ \\
\hline Argentina & 0,51 & $(\ldots)$ & $(\ldots)$ & 1,7 & 2,21 \\
\hline Brasil & 1,11 & 0,45 & 0,66 & 1,18 & 2,29 \\
\hline Chile & 4,21 & 0,9 & 3,31 & 0,76 & 4,97 \\
\hline Colombia & 1,6 & 1,36 & 0,24 & 1,92 & 3,52 \\
\hline Ecuador & 1,2 & 0,4 & 0,8 & 3,4 & 4,6 \\
\hline Guatemala & 5,28 & 0,93 & 4,35 & 2,63 & 7,91 \\
\hline México & 3,02 & 1,45 & 1,56 & 2,9 & 5,92 \\
\hline Nicaragua & $(\ldots)$ & $(\ldots)$ & $(\ldots)$ & $(\ldots)$ & 6,6 \\
\hline Perú & 0,29 & 0,1 & 0,18 & 1,76 & 2,05 \\
\hline Promedio & 2,15 & 0,80 & 1,59 & 2,03 & 4,45 \\
\hline
\end{tabular}

Fuente: Itriago (2011)

Para algunos analistas, sin embargo, la política fiscal en Colombia debe ser todavía objeto de una reforma estructural que garantice el equilibrio en las finanzas públicas y garantice el crecimiento económico a través del jalonamiento del ahorro público, la sostenibilidad fiscal de largo plazo y la inversión privada. De acuerdo con Perry:

[...] el sistema tributario colombiano es complejo y costoso de administrar; tiene muy baja productividad y produce un recaudo insuficiente; no redistribuye y está plagado de inequidades horizontales; causa enormes distorsiones en la asignación de recursos entre sectores; y estimula la informalidad y el desempleo, la desintermediación financiera y un uso ineficiente de los combustibles. Estos problemas se originan, ante todo, en el excesivo número e importancia de los privilegios tributarios en el IVA y los impuestos a la renta (exenciones, deducciones espaciales, tasas preferenciales) y a la existencia de tres 
gravámenes altamente distorsionantes: al empleo formal, al patrimonio empresarial y a las transacciones financieras. (Perry, 2010, p. 38)

Desde el discurso neoliberal, los privilegios, la pluralidad de tarifas y las distorsiones son concebidas como el reflejo de intereses sociales sectoriales que impiden el diseño de una estructura tributaria óptima y garante del "interés general"; es decir, del interés de los empresarios, pues son ellos quienes constituyen el actor fundamental del proceso económico, y es a ellos a quienes debe otorgárseles las condiciones institucionales, legales y de armonía social necesarias para garantizar las lógicas de acumulación. En la práctica, la eliminación de los privilegios, exenciones y distorsiones provenientes de la economía política de la tributación en Colombia implicaría: "simplificar el IVA y los impuestos a la renta (unificando tarifas y eliminando o reduciendo significativamente exenciones y excepciones, rentas exentas y deducciones espaciales) eliminar o reducir los parafiscales, el impuesto al patrimonio de las empresas y a las transacciones financieras; y permitir el descuento pleno del IVA pagado a la adquisición de bienes de capital” (Perry, 2010, p. 9).

Sin embargo, se acepta que en términos netos, una propuesta de este tenor implicaría la reducción de los ingresos del Estado, lo cual entorpecería el logro del objetivo fundamental de la sostenibilidad fiscal en el largo plazo. Esto obligaría a la búsqueda de ingresos que no lastimen los intereses y expectativas del sector privado, y que en consecuencia, terminan vulnerando los intereses sociales de los sectores sociales y populares.

Para garantizar la necesidad de sostenibilidad fiscal y reducir los parafiscales se hace necesario gravar la mayoría de los bienes exceptuados y exentos en el IVA y subir la tasa básica a 19\%, acompañando esta reforma por una compensación parcial a las familias SISBEN 1 y 2 por razones de equidad y viabilidad política y jurídica [...] el riesgo jurídico de una reforma que grave con IVA productos básicos antes exceptuados o exentos se puede mitigar destacando la ampliación reciente del programa de Familias en Acción y estableciendo una compensación parcial para los estratos SISBEN 1 y 2. (Perry, 2010, pp. 10-12)4

La afirmación de Perry demuestra que la mayor explotación tributaria conduce a una mayor necesidad de gasto social:

\footnotetext{
${ }^{4}$ De hecho, Perry (2010) acepta que ante los "riesgos reputacionales" que ocasionaría un cambio abrupto en la normatividad, es posible que los privilegios y condiciones favorables ofrecidas al capital privado mediante las gabelas tributarias y los Contratos de estabilidad jurídica en el gobierno de Álvaro Uribe Vélez (2002-2010), deban mantenerse. Esto implicaría un costo fiscal que debería ser subsanado mediante el aumento generalizado del IVA no al $19 \%$ sino al $21 \%$.
} 
Esta es una interesante contradicción del sistema fiscal: por una parte, la clase trabajadora es la que soporta el mayor peso de los impuestos; por otra parte, esta misma clase necesita de una cantidad creciente de gastos (consumo social y gastos sociales) debido precisamente a su condición de clase trabajadora. Puede ser muy bien verdad que cuanto mayor es el grado de explotación fiscal, mayor debe ser el nivel de los gastos estatales y de ahí la necesidad de una explotación fiscal todavía mayor. (O’Connor, 1994, p. 262)

Es claro el conflicto que en este sentido se presenta entre los derechos sociales y económicos de los colombianos y los “derechos del capital”. El modelo de reforma óptima implica un incremento de la carga tributaria en los sectores sociales con menores ingresos, pues por su naturaleza el IVA castiga de igual forma a los consumidores independientemente de su riqueza o nivel de ingreso. La mayor explotación tributaria socava, entonces, el ejercicio de derechos económicos y sociales en Colombia, aumenta la desigualdad y sería la causa de mayores presiones sobre el gasto asistencial de la política social.

\section{Acumulación: las presiones por la ampliación del stock de capital físico, humano y de CT+I}

Durante la década de 1980, el gasto público fue comprendido desde la perspectiva de la estabilidad y el ajuste macroeconómico. El equilibrio de las finanzas públicas fue concebido como un imperativo incuestionable e inaplazable. Sin embargo, en el marco de las reconfiguraciones históricas del Consenso de Washington de 1990, esta postura ha sido matizada y se ha insistido en que los procesos de estabilización y ajuste estructural emprendidos en América Latina durante la década de 1980 han resultado ambiguos en términos de los efectos negativos que dichas restricciones generan en el largo plazo en materia de crecimiento económico y solvencia fiscal.

Por ejemplo, la comprensión del ajuste fiscal como piedra angular de la estabilidad macroeconómica, ha generado efectos perversos en términos del gasto y la inversión pública destinada a infraestructura. Este hecho puede ser explicado por la estrechez de los argumentos que asumen los recortes al gasto en infraestructura física un medio válido para el ajuste fiscal. En este sentido, desde la reconfiguración del discurso neoliberal se ha demandado la creación de nuevos modelos de valoración fiscal que tomen como base horizontes temporales extensos asociados con las dinámicas de retorno de la inversión, el crecimiento y la solvencia fiscal de largo plazo. La austeridad aplicada a temas de infraestructura, se convertía en una restricción a los procesos de acumulación:

La restricción fiscal implementada mediante recortes en el gasto público en infraestructura representa una estrategia de ajuste miope y potencialmente autodestructiva, porque disminuye el producto futuro de la economía y, en consecuencia, la recolección de impuestos y la capacidad de pago de la deuda de la economía. (Easterly y Servén, 2003, p. 75) 
La apertura a la iniciativa privada, además, no fue la panacea para las grandes dificultades de la infraestructura en América Latina. Esto permite concluir que, si se tiene en cuenta que la inversión en infraestructura constituye un antecedente robusto de los subsiguientes cambios en el stock de infraestructura, la reducción en el gasto público ha afectado negativamente la cantidad de infraestructura disponible en América Latina en las dos últimas décadas. Ni siquiera es claro que el gasto privado en infraestructura se traduzca en una acumulación de stock más rápida y eficiente. Ante este panorama, la pregunta se centra en los efectos que la brecha en infraestructura -producida por la reducción del gasto en el marco de las dinámicas de estabilización y ajuste macroeconómico- genera sobre variables como el crecimiento económico y la acumulación capitalista.

Dada la restricción presupuestal que han enfrentado los gobiernos, una de las herramientas más utilizadas para asegurar las inversiones en este sector son las denominadas vigencias futuras:

El monto total de los cupos de vigencias futuras autorizados para el periodo 2011-2027, con corte al 30 de abril de 2010, suma \$30,5 billones, en pesos constantes de 2010 [...]. Este valor incluye las autorizaciones de varias administraciones presidenciales y los avales fiscales otorgados en la segunda administración Uribe por valor de $\$ 4,2$ billones, que no han completado su trámite de aprobación de vigencias futuras con cargo a presupuestos de los próximos años. De los $\$ 30,5$ billones, $\$ 3,2$ billones son cupos autorizados en las administraciones Samper y Pastrana (Metro, Fogafin y concesiones viales, entre las más representativas), las cuales cubren hasta el año 2022. Estos cupos se ejecutarían principalmente en las siguientes dos administraciones presidenciales. Los restantes $\$ 27,3$ billones son cupos autorizados y avales aprobados durante las administraciones del presidente Uribe Vélez para el periodo 2011-2027, de los cuales se estima que $\$ 17,7$ billones (65\%), se ejecutarían durante la próxima administración presidencial (2010-2014), como parte de los respectivos planes nacionales de desarrollo [...]. Por sectores, en el corto y mediano plazos las vigencias futuras de inversión se concentran principalmente en aquellos que desarrollan proyectos que buscan incrementar los niveles de desarrollo humano y formación de capital fijo. A partir de 2011, la gran mayoría de las vigencias futuras se encuentran en los sectores transporte $(85,5 \%)$ y hacienda (14,2\%), donde los recursos de este último, representan compromisos de la Nación en el desarrollo de sistemas integrados de transporte masivo (SITM) en diferentes ciudades del país. (Ministerio de Hacienda y Crédito Público, 2010a, p. 96)

Más aun, se ha insistido en que en el marco de las evidentes restricciones fiscales "se requiere un modelo capaz de atraer capital privado en gran escala para financiar y construir la columna vertebral de la red vial principal [...]. Las concesiones son instrumentos financieros ideales para lograr este propósito, a través de la financiación privada de la 
infraestructura vial" (Benavides, 2010, p. 281). Esto en el marco del establecimiento de garantías para el sector privado como la definición de vigencias futuras, la creación de peajes, la cesión de derechos exclusivos de desarrollo de finca raíz en las vías aledañas, y el establecimiento de "peajes sombra"; es decir, de pagos periódicos por parte del sector público al concesionario para lograr la rentabilidad privada y reducir la presión sobre los pagos de los usuarios.

A los gastos en capital físico (infraestructura) destinados al cumplimiento de la función de acumulación, es necesario también añadir los gastos en “capital humano". La inversión en recursos humanos fue reconocida desde siempre por el neoliberalismo como un medio esencial para encontrar relaciones de complementariedad entre el cambio técnico y la mano de obra. En este contexto, la inversión en recursos humanos constituye la mejor alternativa para encontrar un punto de equilibrio entre la búsqueda de mayores niveles de productividad y la minimización de la pobreza. Behrman (1993) testifica la relación virtuosa que se establece entre crecimiento económico e inversión en recursos humanos: las mayores tasas de escolaridad se relacionan con reducciones en la fecundidad y mortalidad, con niveles inferiores de analfabetismo, con mejoras de bienestar y salud y con la consolidación de la masa trabajadora cualificada requerida para el mejor desempeño económico. Así mismo, altos grados de salud y nutrición favorecen la esperanza de vida, disminuyen las presiones demográficas y, en el largo plazo, minimizan las presiones fiscales generadas por los gastos en salud curativa. Por último, los programas de adiestramiento de la mano de obra aumentan la rentabilidad y productividad del sector privado.

Esta lógica establecía claros criterios de rendimiento en términos de rentabilidad y beneficios mediante la comparación del desempeño del sector público y el sector privado en la prestación de dichos servicios. En efecto, a fin de incrementar los rendimientos de la inversión en términos de rentabilidad y beneficios, se requería partir de una relación de complementariedad entre Estado y mercado y tener presentes criterios de focalización y priorización sustentados en las siguientes premisas: i) para los países intermedios resultan bastante considerables los aumentos de productividad derivados de inversión en educación básica; ii) en aquellos países en que la salud y nutrición son deficientes, puede obtenerse un mayor rendimiento mediante el control de enfermedades infecciosas y la atención materno-infantil, y iii) las tasas de rentabilidad de las inversiones adicionales en recursos humanos femeninos tienden a ser superiores a las de los hombres, en parte, debido al impacto positivo que tiene la escolaridad femenina sobre la salud, la nutrición, la fecundidad y el crecimiento económico.

Estos han sido los criterios que han configurado el régimen de transferencias departamentales y municipales en Colombia. En efecto, las inversiones en educación, salud y agua potable y alcantarillado para los cuales deben ser destinadas las transferencias han sido concebidas en términos de inversión en recursos humanos y lógicas de 
complementariedad Estado-mercado. En la figura 4 se presentan las transferencias a departamentos y municipios las cuales muestran un claro comportamiento ascendente, pasando de representar 0.1 billones de pesos en 1990 a 31.4 billones de pesos en 2013.

\section{Figura 4}

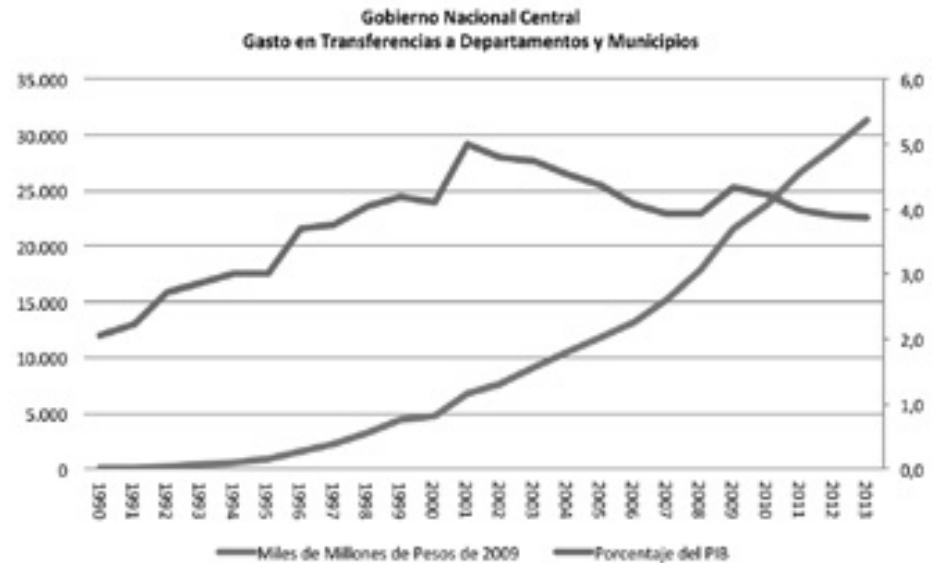

Fuente: Ministerio de Hacienda y Crédito Público. Cálculos propios

Durante este periodo, las transferencias regionales han representado, en promedio, el 30\% de los gastos totales de la Nación y el 35\% de los gastos en funcionamiento. Como proporción del PIB, las transferencias han pasado de representar el 2.1\% en 1990 al 5\% en 2001, y descendiendo al 3.8\% en $2013^{5}$.

Por último, otro factor clave en los rubros fiscales relativos a la función de acumulación son los gastos en ciencia, tecnología e innovación (CT+I). En las reconfiguraciones más contemporáneas del neoliberalismo, el sustento de la competitividad y de la ampliación de la base exportable del país con bienes de mayor valor agregado se encuentra en la generación, difusión y uso del conocimiento. El cambio técnico constituye el motor del crecimiento y

${ }^{5}$ El régimen de transferencias establecido por la Constitución Política de 1991 fue reformado mediante el Acto Legislativo 01 de 2001, que creó el Sistema General de Participaciones, escindió los ingresos corrientes de la Nación de los recursos transferidos a departamentos y municipios, y estableció criterios de subsidio a la demanda para la distribución de los recursos. Dicha reforma se asumía como "transitoria", y perdería vigencia en 2008. Sin embargo, mediante el Acto Legislativo 11 de 2007 se estableció una nueva reforma que modificó la base de liquidación para incrementar anualmente las trasferencias a entidades territoriales. El nuevo sistema se inició en 2008 y fijó un crecimiento del Sistema General de Participaciones del 4\% real entre 2008 y 2009, del 3.5\% en 2010, y del 3\% en 2011 y hasta 2016. De acuerdo con Rodríguez (2007), en comparación con lo que se estableció originalmente en la Constitución de 1991, estas reformas implican una pérdida de recursos para los entes territoriales que asciende a 63 billones de 2006 entre 1994 y 2016. 
el desarrollo económico y social. Sin el apoyo del Estado es impensable un modelo económico productivo y competitivo en el marco de la sociedad del conocimiento: "El gasto privado en I+D así como el nivel de actividad científico-tecnológica serán subóptimas, relativo al nivel socialmente deseable si se deja al mercado actuar por su cuenta. Existen diversas fallas de mercado asociadas al fenómeno del desarrollo científico y tecnológico y de la innovación que hacen necesaria la intervención del Estado" (Perfetti, 2010, p. 323).

Sin embargo, tal y como lo sostiene la "nueva economía”, dicha intervención del Estado debe concentrarse en el establecimiento de incentivos para la inversión en CT+I. Y dichos incentivos, únicamente se hacen concretos cuando las inversiones son rentables; es decir, cuando se imponen derechos de propiedad sobre el conocimiento. La rentabilidad de las inversiones en capital humano e investigación e innovación es garantizada cuando un entramado institucional adecuado ofrece posibilidades de capturas de renta a través de la definición precisa de derechos de propiedad (patentes, derechos de propiedad intelectual e ingresos por nivel educativo). Con ello, la intervención del Estado eliminará las fallas del mercado en el campo de la CT+I y promoverá las externalidades positivas que estas mismas actividades generan.

Sin embargo, el gasto estatal destinado a este campo es precario, razón por la cual, se plantea recurrentemente la necesidad de aumentar el volumen de recursos destinado. En la actualidad, Colombia únicamente dedica el 0.46\% del PIB a estas actividades, y los recursos han sido fluctuantes y no permanentes. De acuerdo con los defensores de la "nueva economía" se requeriría, entonces, un aumento del gasto público destinado a formular un programa nacional de innovación como alianza público-privada y liderada por Colciencias, pero ejecutada por el Consejo Privado de Competitividad. Recientemente, el Consejo Nacional de Educación Superior (2014) ha establecido la necesidad de aumentar el gasto en actividades de CT+I hasta alcanzar un umbral del 1.5\% del PIB. Alcanzar este objetivo requerirá un incremento del gasto del 10\% anual entre 2015 y 2034.

\section{Legitimidad: la configuración de un Estado bélico-asistencial}

A partir del año 2002, la Política de Defensa y Seguridad Democrática se ha constituido en el pilar sobre el cual se desarrollan las demás estrategias con el propósito de generar confianza en los inversionistas nacionales y extranjeros y lograr mayor crecimiento económico y bienestar. Desde los primeros años de gobierno de Uribe Vélez, se sostuvo que el mayor gasto militar demandado por la Seguridad Democrática generaría un beneficio neto para la economía colombiana, vinculado a la reducción de la destrucción del capital privado y el trabajo, los incrementos en la productividad marginal, el incremento en el stock de capital, el aumento del producto, el impulso al empleo y el mayor bienestar social (Arias y Ardila, 2003). Bajo esta convicción, se incrementó de manera notable el gasto público destinado a seguridad y defensa, y se profundizó la tendencia observada 
desde 1990. En efecto, como lo muestra la figura 5, el gasto en seguridad y defensa se ha incrementado notoriamente entre 1990 y 2013, pasando de menos de un billón de pesos en 1990 a 27 billones en 2014. El volumen de gasto en seguridad y defensa ha incrementado del 2.2\% del PIB en 1990 al 5.9\% en 2014.

\section{Figura 5}

Colombia. Gasto en Seguridad y Defensa

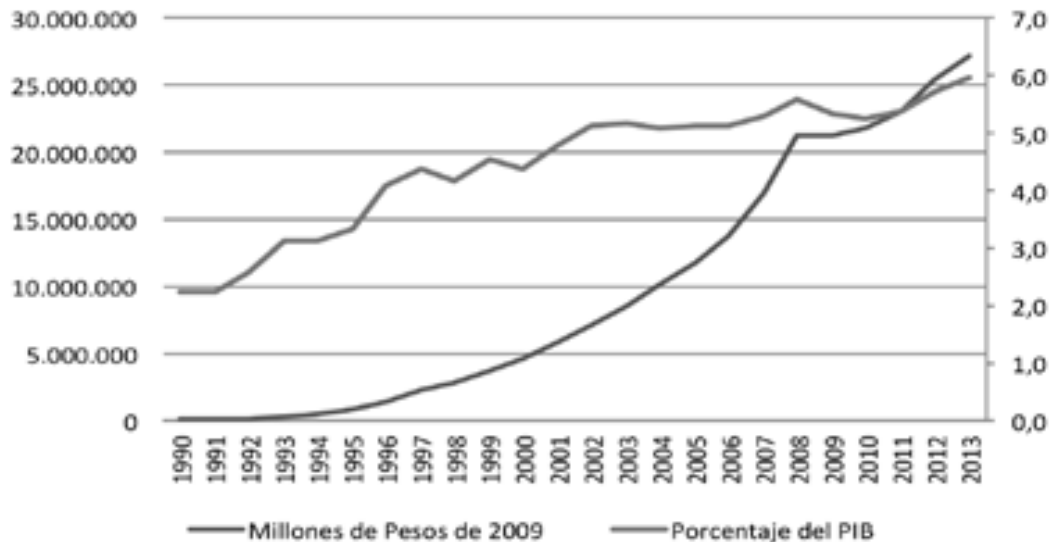

Fuente: Departamento Nacional de Planeación. Cálculos propios

Las críticas a este modelo son múltiples. Varios analistas han señalado la enorme presión que ejerce el gasto en seguridad y defensa sobre las finanzas públicas del país. En efecto, de acuerdo con el Departamento Nacional de Planeación (2014), el 90\% de este presupuesto en seguridad y defensa es destinado a gastos en funcionamiento (pensiones, salarios, bienes y servicios destinados a garantizar la operación del sector, y financiamiento de los establecimientos públicos del sector) y solo el 10\% restante a gastos de inversión. La presión generada desde al gasto en defensa y seguridad, unida a su inflexibilidad, ha llevado a subrayar la necesidad de hacer permanente el impuesto al patrimonio, a anticipar una nueva reforma tributaria y a cuestionar las bondades de las políticas de estímulo tributario (exenciones, deducciones, exclusiones y descuentos) a la inversión privada promovidas por el gobierno de Uribe Vélez, de cara a la conversión de Colombia en un "paraíso fiscal” (Acosta, 2009) ${ }^{6}$.

\footnotetext{
${ }^{6}$ Recientemente, el Departamento Nacional de Planeación ha indicado que: "estos gastos generan impactos presupuestales presentes y futuros con un alto nivel de inflexibilidad. Por una parte, el crecimiento en el número de soldados y policías implica no solo un aumento en los gastos de personal, sino también los asociados a su dotación, la provisión de servicios de salud y vivienda, y a las futuras asignaciones de retiro. Por otra parte, las recientes inversiones en la adquisición
} 
Por otra parte, también han sido resaltados los costos de oportunidad de la seguridad democrática en términos de inversión en salud, educación y saneamiento básico, y se ha puesto en duda la racionalidad de una política de confrontación abierta que no intenta transformar las condiciones de marginalidad, pobreza y exclusión que incrementan las posibilidades de reclutamiento por parte de los grupos armados ilegales (Isaza y Campos, 2008)

Sin embargo, lo más notable en los últimos veinte años es que el mayor gasto en seguridad y defensa se ha visto acompañado por incrementos importantes en el gasto social. En efecto, tal y como lo muestra la figura 5, el gasto social ha pasado de 1.3 billones en 1994 a 110 billones de pesos en 2013. Vale anotar que, aunque no ha tenido el mismo dinamismo, el gasto social diferente al asociado con las transferencias ha aumentado, pasando de 0.3 billones en 1994 a 25 billones en 2013. Entre 1994 y 2013 el gasto social diferente de las transferencias ha representado, en promedio, el 21\% del total del gasto público en Colombia (figuras 6 y 7 ).

y modernización de equipos y construcción de infraestructura producen crecientes demandas de recursos para cubrir los ciclos de mantenimiento y garantizar su operación. En conclusión, se plantea la necesidad de evaluar mecanismos alternativos de financiación una vez se concluya el recaudo del actual impuesto al patrimonio. El agotamiento de las fuentes alternas de financiación impactaría las capacidades de la Fuerza Pública al poner en riesgo la continuidad de los procesos de modernización a través de nuevas inversiones, y limitar el sostenimiento de las capacidades adquiridas en los últimos años. Adicionalmente, es indispensable que dichos mecanismos sean sostenibles en el largo plazo, teniendo en cuenta dos aspectos trascendentales: (1) generar las condiciones necesarias para mantener unas finanzas públicas equilibradas, y (2) garantizar la operatividad de una Fuerza Pública capaz de adaptarse a los nuevos retos y tareas que deberá afrontar en el marco de un escenario de posconflicto y consolidación de la paz" (Departamento Nacional de Planeación, 2014, p. 25).

${ }^{7}$ En términos fiscales, la eficiencia de la política de seguridad y defensa es totalmente cuestionable: "Manteniendo una hipótesis muy conservadora, que solo el 30\% del gasto militar se dirige a la lucha contrainsurgente, y que la totalidad de las cifras de "efectividad" del combate publicadas por el gobierno corresponden a bajas guerrilleras y no a ejecuciones extrajudiciales [...] se tiene [para el año 2006] "costo unitario" por baja, capturas o desmovilización de un guerrillero $\$ 616$ millones [...] el resultado es más desconcertante, si se tiene en consideración que de cada 100 guerrilleros retirados, 84 nuevos entran a la subversión, lo cual implica que para lograr un retiro "efectivo" en un periodo de 4 años, el costo económico supera los $\$ 1000-\$ 1500$ millones. Comparando el año 2006 con el 2005, se observa que de los 9.565 guerrilleros retirados del combate la subversión pudo reclutar 8.523, pues la reducción efectiva fue de 1042 armados ilegales. Es decir, para lograr un retiro "efectivo" y con la hipótesis de solo asignar el $30 \%$ a la lucha contrainsurgente, la cifra es un alucinante $\$ 5.662$ millones por cada retiro efectivo" (Isaza y Campos, 2008, p. 40). 


\section{Figura 6}

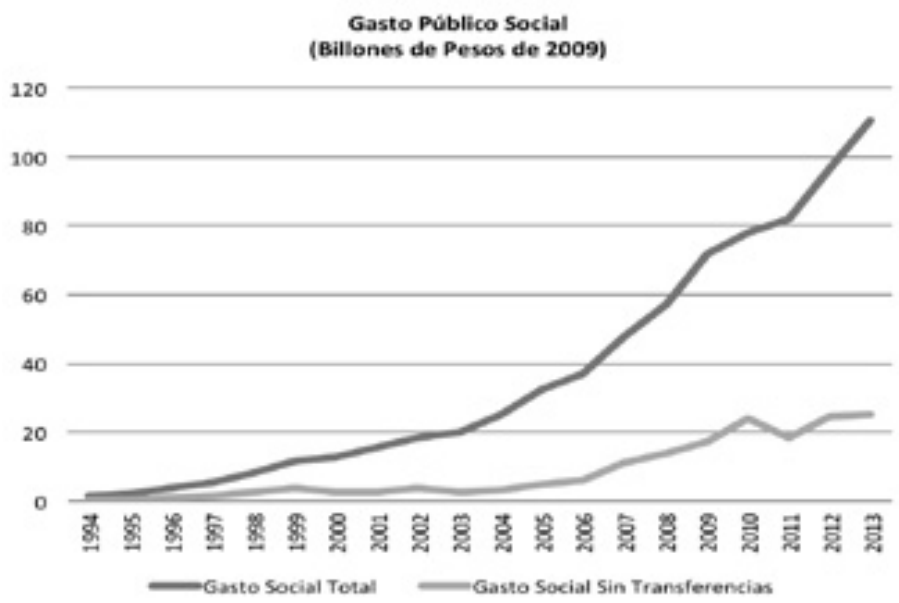

Fuente: Ministerio de Hacienda y Crédito Público. Cálculos propios.

\section{Figura 7}

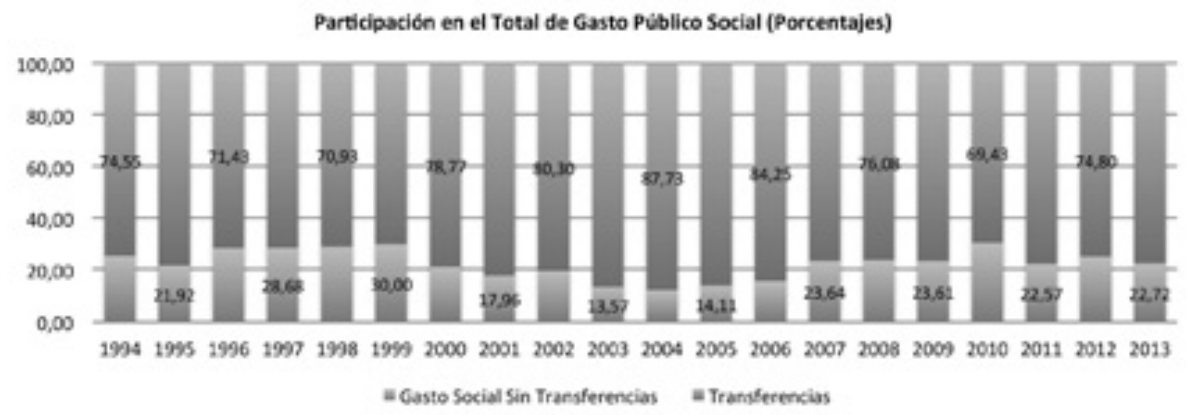

Fuente: Ministerio de Hacienda y Crédito Público. Cálculos propios.

Sin embargo, el mayor volumen de gasto público social no es sinónimo de existencia de una verdadera política social, pues los discursos de "la inversión en recursos humanos", "la lucha contra la pobreza" y "el manejo social del riesgo" no atacan las causas estructurales de la pobreza y la desigualdad; razón por la cual, han sido siempre subrayados sus rasgos compensatorios y remediales:

[...] las políticas de lucha contra la pobreza pueden ser definidas como políticas de compensación parcial del fracaso de las políticas sociales; esto es, por no atacar las causas sociales de la pobreza, estas políticas reproducen permanentemente las condiciones que las generan. Esta distinción entre la lucha contra la pobreza y la lucha contra sus causas sociales (las 
que se pueden agrupar bajo el término de "vulnerabilidad") constituye el fundamento de las políticas sociales modernas. (Lautier, 2005, p. 95)

El problema radica en que, evidentemente, el modelo neoasistencialista imperante contiene pretensiones de contención social y subordinación política, pues es proclive al clientelismo, es funcional a las apuestas re-centralistas del régimen político y constituye, en realidad, una salida remedial que no cuestiona las lógicas de generación de riqueza y que se concentra únicamente en el combate a la pobreza (Rodríguez, 2007). De hecho, dicho modelo ha sido clave en los objetivos de "consolidación de territorios" de la política de Seguridad Democrática, y en la doctrinas de “Acción Integral” de carácter contrainsurgente que se han profundizado durante la última década en Colombia:

[...] La Doctrina de Acción Integral es una respuesta seria a las limitaciones de acción militar como única forma de actuación en el combate a los adversarios del Estado o, si se prefiere, para consolidar la presencia del aparato estatal. En paralelo, se reconoce que el primer paso necesario para instalar el Estado en los territorios que resisten sigue siendo la fuerza armada, que es la que permite despejar el territorio de enemigos para ejercer el control estatal, pero con el agregado de que esta acción armada por sí sola, es insuficiente. Para los estrategas militares, es preciso desarrollar herramientas y mecanismos que le permitan al Estado hacer un combinado e integral de su fuerza legítima y de la acción social, en su objetivo de ir consolidando, progresivamente, el control del territorio nacional. (Zibechi, 2010, p. 8)

De otra parte, se ha demostrado que el mayor potencial redistributivo del gasto público se encuentra en aquellas políticas sociales de corte universalista, como la educación, la salud, la nutrición y algunos programas condicionados. Esto, contrario a lo que ocurre con programas de cobertura intermedia como la educación secundaria, la vivienda y el saneamiento básico, y a lo que sucede con las políticas de gasto que tienden a concentrarse como la educación superior y la seguridad social. Sin embargo, aunque en Colombia ha aumentado progresivamente el gasto social, sus principios rectores (basados en la focalización y la profundización de los subsidios a la demanda) hacen que su efecto redistributivo sea mínimo. Lo anterior indica la necesidad de replantearse los principios del gasto público en consonancia con lo establecido por la evidencia empírica y el enfoque de los derechos en cuanto al fortalecimiento de las políticas con enfoque universalista:

El objetivo social debe ser la universalización y que esa tarea generará en el margen gasto social altamente progresivo. [...] Como los sistemas universales son por definición más costosos, el esfuerzo de la generación de recursos es ineludible, y lo será más para romper la desigualdad en sociedades altamente desiguales. [...] La asistencia social y los esfuerzos 
de focalización que los acompañan podrán hacer una contribución marginal, pero no por ello menos importante, especialmente para combatir la pobreza extrema, adaptar los programas a características específicas de algunas poblaciones (v.gr., indígenas) y garantizar que las poblaciones que tienen dificultades para acceder a los servicios básicos universales puedan hacerlo. (Ocampo y Malagón, 2012, p. 93)

La coexistencia de enormes gastos en seguridad y defensa, unidos a incrementos sostenidos en gasto asistencial constituyen elementos imprescindibles para encontrar las claves de la legitimidad, la estabilidad y la relativa armonía social sobre la cual se despliega y reconfigura el orden neoliberal en Colombia. El clientelismo propio de las lógicas de asistencia social, unidas a los dispositivos de contención y cooptación social que estas medidas implican, constituyen elementos complementarios a las lógicas militaristas y represivas sobre las cuales el Estado en Colombia asegura la "consolidación" de sus territorios. Las consecuencias sociales perversas del orden neoliberal y las implicaciones que dicho orden tiene para la dinámica del conflicto interno armado, se regulan a través de la edificación de un Estado bélico-asistencial, garante de arreglos que aseguran la lealtad de ciertos sectores sociales, pero, determinante igualmente de gastos crecientes que explican la crisis fiscal del Estado colombiano.

\section{Confianza: el camino hacia el principio constitucional de la sostenibilidad fiscal}

Desde el Consenso de Washington de 1990 la política fiscal fue concebida como la piedra angular del ajuste macroeconómico. Desde el ideario neoliberal un presupuesto público austero y tendiente al equilibrio garantizaría el flujo de recursos financieros adecuado para fortalecer la inversión privada, mantener una inflación baja y estable, controlar el endeudamiento público, disminuir las tasas de interés y garantizar la estabilidad cambiaria y externa. En este contexto, los sucesivos acuerdos establecidos con el Fondo Monetario Internacional y las "señales" de confianza que deben ser enviadas al capital financiero internacional, ha llevado a la adopción de políticas perversas que, como lo muestra la figura 8, han llevado a recortes permanentes en los gastos destinados a inversión pública (principalmente entre 1998 y 2006), aunque no han logrado recuperarse hasta alcanzar el máximo de 20\% del total de gasto que se observó en 1991. Esto ha sido una consecuencia del incremento sostenido del saldo, el servicio y los intereses de la deuda (figuras 9 y 10). 


\section{Figura 8}

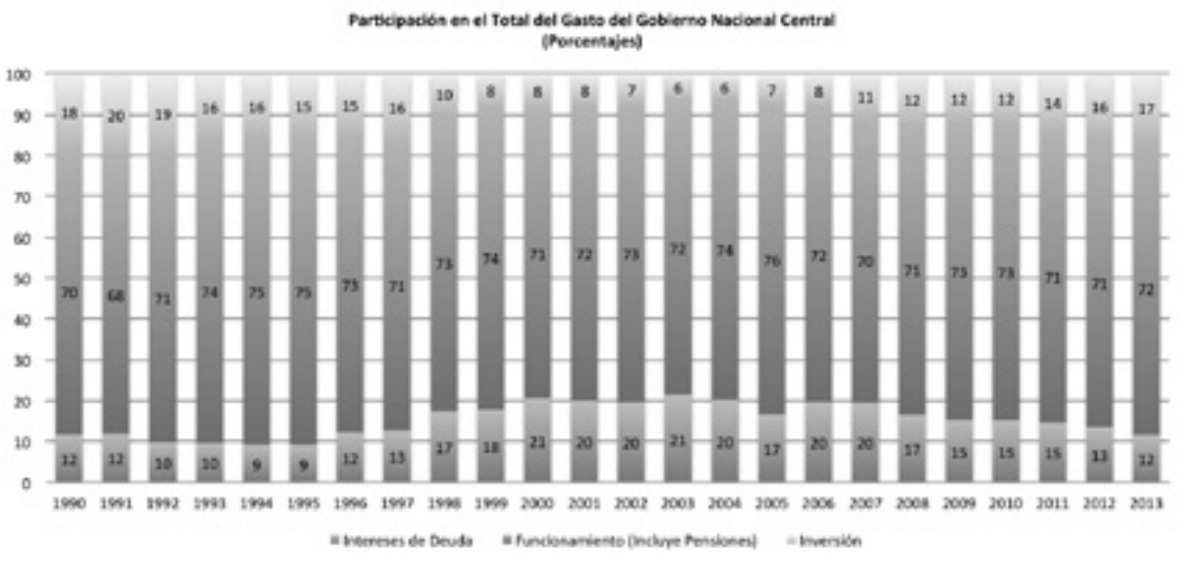

Fuente: Ministerio de Hacienda y Crédito Público. Cálculos propios.

En efecto, el saldo total de la deuda del Gobierno nacional central se ha quintuplicado a pesar de los también cuestionados intentos de recambio de deuda externa por deuda interna. Llama la atención también, el incremento sostenido en el volumen de intereses cancelados, que incluso, exhiben ascensos en momentos en que las amortizaciones disminuyen, lo cual es prueba de la carga extrema que ha padecido el país en aras del cuidado de la confianza y el mantenimiento del calificativo de "buen deudor". En promedio, entre 1990 y 2013 el pago de intereses ha ascendido al 61\% del pago en amortizaciones.

\section{Figura 9}

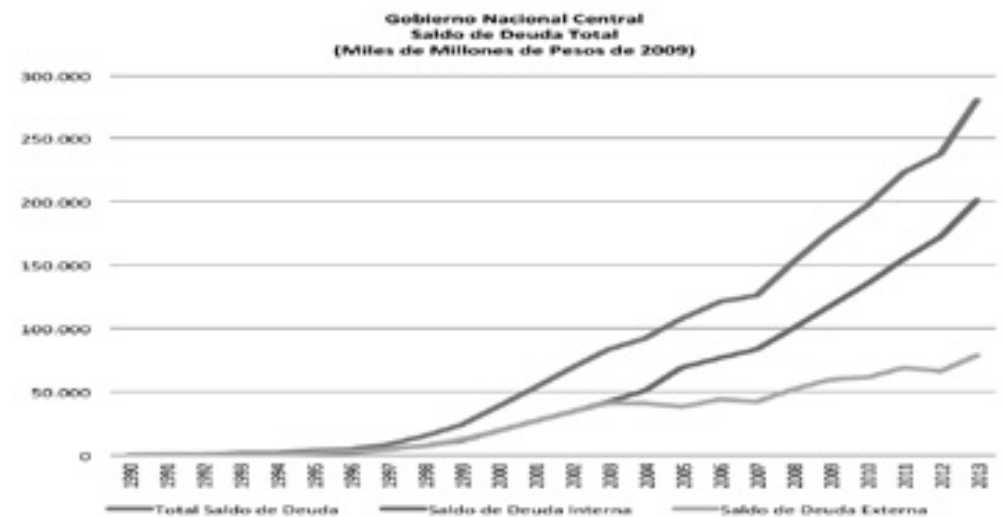

Fuente. Banco de la República. Cálculos propios. 


\section{Figura 10}

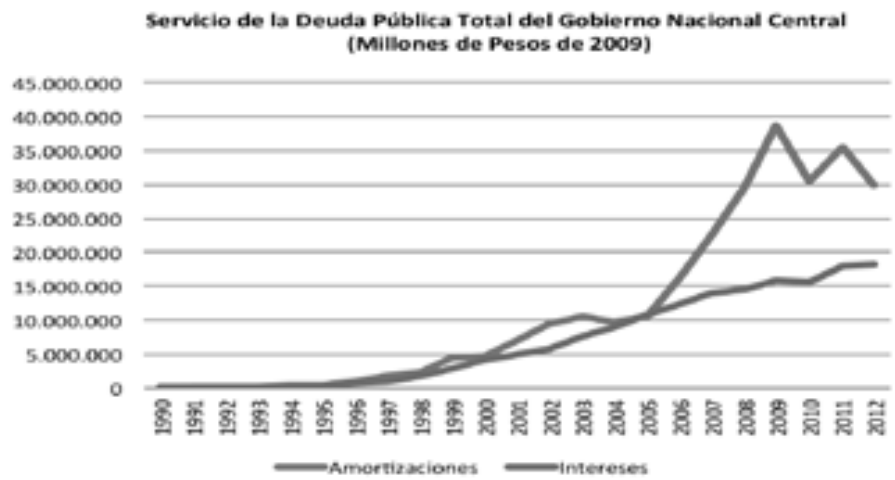

Fuente: Contraloría General de la República. Cálculos propios.

De hecho, al aumento en el saldo de la deuda y el pago de intereses puede ser muestra de un proceso de autonomización de la deuda, en el cual la explicación del mayor nivel de endeudamiento es la deuda en sí misma: "Al contratarse créditos para pagar otros créditos previos y al alejarse el déficit acumulado cada vez más del primario, se ha ido consolidando un 'círculo vicioso déficit-deuda-déficit-deuda' que caracteriza la encrucijada de la política fiscal colombiana" (Betancourt, 2005, p. 374). En este sentido, las posibilidades de saneamiento fiscal dependerían también de la evolución de la política monetaria y de los efectos que esta traiga en el marco de la implementación del modelo de "inflación objetivo" que ha caracterizado la economía colombiana después de 1991:

El saneamiento fiscal no depende del aumento de los ingresos y la disminución de egresos por parte del Estado. En situaciones de endeudamiento, el equilibrio de las finanzas públicas depende también de los impactos provocados por la política monetaria y los eventuales costos fiscales que esta pueda generar en términos de servicio de deuda, según la evolución de las tasas de interés, el tipo de cambio y el uso del señoriaje. (González y Cabrera, 2000, p. 34)

Es claro entonces que el imperativo de un manejo adecuado del servicio de deuda como prerrequisito para acceder a créditos internacionales, financiar el déficit y evitar la competencia con el sector privado en la consecución de recursos financieros, ha dominado la dirección de la política fiscal en los últimos veinticinco años en Colombia. Recientemente, dicha tendencia se ha profundizado en la formulación de una regla de política fiscal para Colombia ${ }^{8}$. En efecto, bajo el objetivo de garantizar la sostenibilidad de la deuda del

${ }^{8}$ El gobierno de Juan Manuel Santos impulsó la reforma constitucional que introdujo el "derecho a la sostenibilidad fiscal" como "un derecho de todos los colombianos", así como el mecanismo 
Gobierno nacional central en el mediano plazo, la regla cuantitativa pretende convertirse en el instrumento que compromete a la autoridad fiscal ante el público y los mercados para anclar las expectativas sobre la sostenibilidad fiscal del país y alcanzar el grado de confianza exigido por el sector financiero nacional e internacional. Dice el Gobierno:

Al convertirse en un ancla de la política fiscal y reducir hasta cierto punto su discrecionalidad, la regla facilitará la coordinación en el manejo de la política económica, y reducirá la incertidumbre de los mercados. Esto incrementa la coherencia intertemporal de las decisiones de los agentes y aumenta la credibilidad de las metas propuestas. Como resultado, cabe esperar menores primas de riesgo y mejores condiciones en los mercados financieros locales e internacionales. El beneficio sobre la sociedad se manifestará, entonces, en menores costos de uso del capital, menor volatilidad macroeconómica y, en general, en un mejor ambiente para la inversión, todo lo cual favorecerá el crecimiento económico de largo plazo. (Ministerio de Hacienda y Crédito Público, 2010a, p. 17)

Sin embargo, las implicaciones económicas, políticas y sociales de esta apuesta son amplias y van en contravía de las exigencias relativas a la posibilidad de edificar un régimen socioeconómico justo y garante de los derechos económicos y sociales ¿Cuál es la estructura presupuestal que la regla fiscal impone en Colombia?

1. Una estructura garante de las condiciones de confianza impuestas por el capital financiero nacional e internacional. Las tesis fiscalistas que sustentan la propuesta de regla fiscal toman como único imperativo alcanzar el calificativo de

que supuestamente lo hace efectivo: la llamada "regla fiscal" (Ministerio de Hacienda y Crédito Público, 2010b, p. 16). De acuerdo con el Ministerio de Hacienda y Crédito Público, la regla fiscal propuesta para Colombia es la siguiente:

$$
\mathrm{Bt}^{\mathrm{B}}=\mathrm{B}^{*}+0,3 \mathrm{Yt}+\mathrm{CCIPt}
$$

Donde,

- Bt: es el balance fiscal primario del Gobierno nacional central.

- $\quad B^{*}$ : es el balance fiscal primario objetivo que hace sostenible la deuda en el mediano plazo.

- Yt: es la brecha del producto en la economía colombiana.

- CCIPt: es el componente cíclico de los ingresos petroleros del Gobierno nacional central.

De esta forma, la regla fiscal establece el nivel del balance fiscal primario que debe lograr la autoridad fiscal en cada momento del tiempo, una vez descontados los efectos del ciclo económico y de los ingresos petroleros sobre sus finanzas. "Así, se requerirá un mayor superávit (o menor déficit) cuando el crecimiento de la economía se ubique por encima de su nivel potencial y/o los ingresos petroleros estén por encima de su senda de largo plazo y, por el contrario, se permitirá un menor superávit (o mayor déficit) cuando el crecimiento de la economía se ubique por debajo de su nivel potencial y los ingresos petroleros estén por debajo de su senda de largo plazo" (Ministerio de Hacienda y Crédito Público, 2010a, p. 16). 
"buen deudor" del Estado colombiano. La política fiscal y sus componentes serán siempre evaluados en términos de la deuda y su sostenibilidad, y nunca desde la perspectiva de los efectos que sobre el crecimiento, la igualdad, la justicia social o el nivel de empleo tiene la política fiscal. Dice Paul Krugman:

\begin{abstract}
El asunto es que, debido a que los ataques especulativos pueden justificarse a sí mismos, el hecho de seguir una política económica que tenga sentido en términos de los elementos básicos no es suficiente para asegurar la confianza del mercado. De hecho, la necesidad de ganarse esa confianza puede, en efecto, impedir que un país siga políticas sensatas y obligarlo a adoptar unas que normalmente se considerarían perversas. (Krugman, 2004, p. 157)
\end{abstract}

2. Una estructura que profundiza las lógicas de precarización laboral. Debido a que implícitamente la regla fiscal asume la existencia de una tasa "natural" de desempleo, vinculada con la brecha del producto, que únicamente puede reducirse si se apelan a políticas de flexibilización (precarización) laboral.

3. Una estructura que introduce ingresos que no son estables en la definición del balance primario. Pues se ahonda la dependencia del presupuesto público con respecto a los ingresos petroleros. Esto en un contexto en el que las autoridades monetarias no tienen compromisos claros con la estabilidad cambiaria y en el que el país carece de control sobre los precios internacionales del crudo.

4. Un régimen que consolida, simultáneamente, lógicas de centralismo y federalismo fiscal. La regla fiscal exige la consolidación del proceso de federalismo fiscal que se ha emprendido con las reformas sucesivas al régimen de transferencias y con la exigencia de un mayor esfuerzo fiscal por parte de las entidades descentralizadas.

Para asegurar un orden jurídico ajustado a las necesidades del mantenimiento de la confianza, el Gobierno promovió el Acto Legislativo 03 de 2011 "por el cual se establece el principio de sostenibilidad fiscal”. Y en desarrollo del cambio constitucional mencionado, consagró la Ley de regla fiscal (Ley 1473 de 2011) que fue aprobada en julio de 2011 y que entró en vigencia a partir del $1^{\circ}$ de enero de 2012, implementó una regla cuantitativa sobre las finanzas del Gobierno nacional central. Según el Ministerio de Hacienda y Crédito Público, con dicha ley se busca consolidar el proceso de ajuste realizado a lo largo de la última década y fortalecer los objetivos propuestos con la Ley de Responsabilidad Fiscal del año 2003 (Ley 819 de 2003) a través de una programación fiscal establecida en el Marco Fiscal de Mediano Plazo (MFMP).

Específicamente, la Ley 1473 de 2011, ha establecido que el gasto estructural no podrá superar al ingreso estructural en un monto que exceda la meta anual de balance 
estructural establecido. En el mediano plazo, dicha meta consiste en que el déficit estructural del GNC no será mayor a 1\% del Producto Interno Bruto (PIB) a partir del año 2022. Para ello, el GNC seguirá una senda decreciente anual del déficit en el balance fiscal estructural, que le permita alcanzar un déficit estructural de 2.3\% del PIB o menos en 2014, de 1.9\% del PIB o menos en 2018 y de 1.0\% del PIB o menos en 2022.

De esta manera, la Ley 1695 de 2013 que desarrolla el reformado Artículo 334 de la Constitución Política, establece el "Incidente de Impacto Fiscal" de acuerdo con el cual, el Procurador General de la Nación o uno de los Ministros del Gobierno, una vez proferida la sentencia o los autos que se profieran con posterioridad a la misma, por cualquiera de las máximas corporaciones judiciales, podrá solicitar la apertura de un Incidente de Impacto Fiscal, cuyo trámite será obligatorio. De acuerdo con dicha ley, el incidente de impacto fiscal procederá respecto de todas las sentencias o los autos que se profieran con posterioridad a la misma, por las máximas corporaciones judiciales, cuando se altere la sostenibilidad fiscal, con independencia de la postura que haya adoptado dentro del proceso cualquier entidad u organismo de naturaleza pública, aun cuando no haya participado dentro del mismo. Asimismo, la Ley 1695 de 2013 establece que, después de surtidos los plazos establecidos en su articulado, la Sala Plena de la Corte Constitucional, la Sala Plena de la Corte Suprema de Justicia, la Sala de lo Contencioso Administrativo del Consejo de Estado o la Sala Jurisdiccional Disciplinaria del Consejo Superior de la Judicatura, según corresponda, decidirá por mayoría de sus miembros si procede a modular, modificar o diferir los efectos de la misma, sin que puedan cambiar el sentido del fallo, con el objeto de evitar alteraciones serias de la sostenibilidad fiscal.

En Colombia, el camino hacia un acuerdo fiscal redistributivo es cerrado, entonces, por el objetivo de la confianza que, mediante cambios en la Constitución Política de 1991, impone una norma de normas que reafirma el proceso de restauración de poder de la clase capitalista financiera. Bajo los principios constitucionales introducidos por el Acto Legislativo 03 de 2011, las metas establecidas por la Ley de Regla Fiscal y lo dispuesto por la Ley 1695 de 2013 en cuanto al "Incidente de Impacto Fiscal”, es claro que el GNC se compromete con la consolidación del equilibrio en las finanzas públicas y con la búsqueda de un nivel de ingresos tributarios adecuado para cubrir el comportamiento creciente del gasto público en el país. La estructura tributaria de Colombia se convierte, entonces, en un objetivo fundamental de reforma.

\section{Conclusión}

Aunque el orden neoliberal puede ser definido como hegemónico, resulta incorrecto analizarlo sin tener en cuenta las especificidades de los espacios en que se instaura, y las reconfiguraciones que asume en el marco de la dialéctica local-global. Solo bajo esta perspectiva puede comprenderse al Estado como un agente activo e impulsor de la 
economía política neoliberal en realidades históricas, sociales y de relaciones de clase específicas. Las políticas estatales son entonces el reflejo de compromisos sociales que regulan los conflictos y contradicciones producidas por el orden neoliberal sin hacerlas desaparecer; es decir, son formas estabilizadas de relaciones de poder.

La política fiscal no escapa a esta condición general, y bajo las funciones de acumulación, legitimidad y mantenimiento de la confianza actúa como mecanismo de regulación orientado a garantizar la acumulación capitalista neoliberal en un contexto de relativa armonía social. En Colombia, durante los últimos veinticinco años, dichas funciones se han materializado en el incremento del gasto público en infraestructura, capital humano y ciencia, tecnología e innovación para el caso de la función de acumulación; en el aumento de los gastos sociales y de seguridad y defensa para garantizar la función de legitimación, y en el incremento sostenido en los gastos correspondientes al servicio de deuda para brindar confianza inversionista. El resultado ha sido una profunda crisis fiscal explicada por la notable incapacidad que los ingresos provenientes de la mayor explotación tributaria -asociada con la profundización de los esquemas impositivos indirectos y el efecto neutral de la estructura tributaria sobre la distribución- tienen para cubrir ese volumen creciente de gastos.

La figura 11 ilustra bien esta afirmación. En promedio, entre 1994 y 2013, el 58\% del gasto público total ha sido destinado al pago de intereses de deuda, al gasto social y al sector seguridad y defensa. Este porcentaje ha fluctuado desde el punto más bajo en la serie (49\% en 1994) hasta el punto en que estos tres rubros representaron el 67\% del gasto total en 1999 y el 63\% en 2010. Este es el reflejo de la manera como la política fiscal cumple sus funciones reguladoras de acumulación, legitimación y confianza en un contexto en que se intersectan la hegemonía del orden neoliberal, el conflicto interno armado y la injusticia social del país. Se configura así un Estado bélico-asistencial y de confianza inversionista, que bajo diversos dispositivos de represión y contención social recrea de manera contradictoria y siempre imperfecta las condiciones de estabilidad requeridas para la reproducción de la relación social capitalista, a través de un mayor déficit fiscal. 


\section{Figura 11}

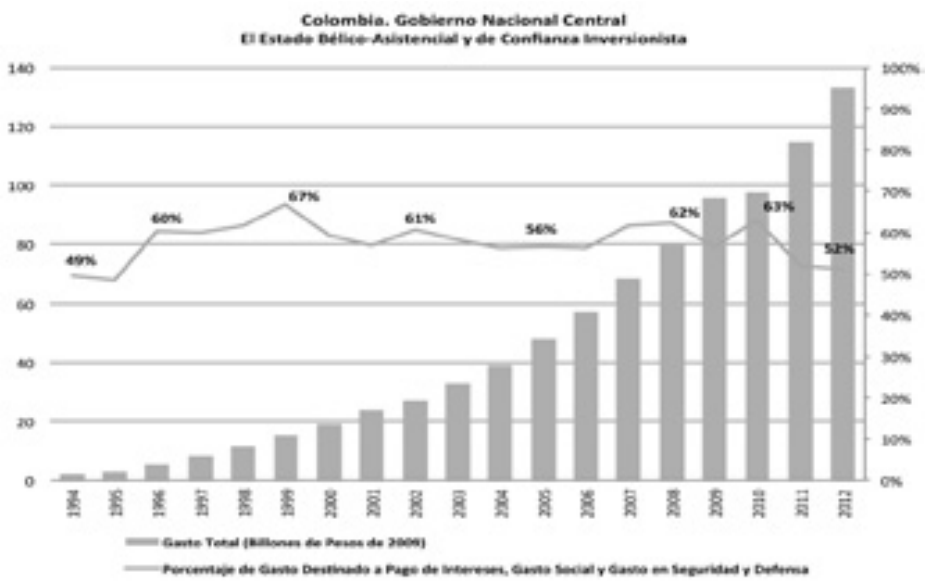

Fuente: Ministerio de Hacienda y Crédito Público, Contraloría General de la República y Departamento Nacional de Planeación. Cálculos propios.

Se demuestra entonces, que más allá de las “inflexibilidades presupuestales" el déficit fiscal en Colombia es el reflejo de aspectos estructurales que trascienden el poder de las autoridades económicas para emprender el ajuste y para los cuales las reformas institucionales destinadas a flexibilizar el presupuesto son totalmente inocuas. El voluntarismo no es el patrón dominante en la definición del presupuesto público. El origen del déficit fiscal en Colombia es político-estructural y no económico-presupuestal. Las reformas tendientes a ajustar los balances públicos a través de mayores ingresos y/o menores gastos serán siempre ineficaces si se ignora que el déficit se mantendrá siempre creciente si el modelo neoliberal se afianza, si se aplaza una salida definitiva al conflicto interno armado del país, y si se insiste en la implementación de modelos asistenciales de política social que no ataquen de manera frontal los procesos sociales de producción y reproducción de la pobreza y la desigualdad. La construcción de paz implica exigentes esfuerzos presupuestales. La crisis fiscal del Estado colombiano no es, por lo tanto, un problema de sumas y restas.

\section{Referencias bibliográficas}

Acosta, A. (2009). Colombia: paraíso fiscal. Foro, 69, 22-28.

Arias, A. y Ardila, L. (2003). Military expenditure and economic activity: The colombian case. Bogotá: Ministerio de Hacienda y Crédito Público.

Behrman, J. (1993). Inversión en recursos humanos. Informe Anual 1993. Washington: Banco Interamericano de Desarrollo, 
Benavides, J. (2010). Reformas para atraer la inversión privada en infraestructura vial. En R. Steiner y V. Traverso (Eds). Colombia 2010-2014: propuestas de política pública (pp.279-320). Bogotá: Fedesarrollo, CAF.

Betancourt, C. (2005). Economía, fiscalidad y necesidad de una tributación redistributiva. En L. J. Garay (Comp.). Colombia: Diálogo pendiente I. Bogotá: Planeta Paz.

Boyer, R. (1992). La teoría de la regulación. Un análisis crítico. Valencia: Edicions Alfons El Magnánim.

Brenner, R. y Glick, M. (1991). La escuela de la regulación: teoría e historia. New Left Review, 21, 5-90.

Buchanan, J. (1984). La economía política del déficit presupuestario. En Ensayos de Economía Política. Virginia: Universidad de Virginia.

Consejo Nacional de Educación Superior (2014). Acuerdo por lo superior. Propuesta de política pública para la excelencia de la educación superior en Colombia en el escenario de la paz. Bogotá: CESU.

Cuadrado, J. (1997). Introducción a la política económica. Barcelona: McGraw Hill.

Departamento Nacional de Planeación (2014). Boletín de seguimiento Consolidación de la Paz, n. ${ }^{\circ}$ 9. Bogotá: Departamento Nacional de Planeación.

Duménil, G. y Lévy, D. (2007). Crisis y salida de la crisis. Orden y desorden neoliberales. México: Fondo de Cultura Económica.

Easterly, W.y Servén, L. (2003). Los límites de la estabilización. Infraestructura, déficit público y crecimiento en América Latina. Bogotá: Banco Mundial, Alfaomega Editores.

Echeverry, J., Fergusson, L. y Querubín, P. (2004). La batalla política por el presupuesto de la nación: inflexibilidades o supervivencia fiscal. Bogotá: Documento CEDE 2004-01, Universidad de los Andes.

Giraldo, C. (2001). Finanzas públicas en América Latina, la economía política. Bogotá: Desde Abajo.

González, J. y Cabrera, S. (2000). El desmanejo de la deuda pública interna. Economía Colombiana, 281, 5-50.

Harvey, D. (2005). A brief history of neoliberalism. New York: Oxford University Press.

Itriago, D. (2011). Dueños del desarrollo. Impuestos para combatir la pobreza. Informe de Investigación de Intermón OXFAM. Septiembre, 2011.

Isaza, J. y Campos, D. (2008). Consideraciones cuantitativas sobre la evolución reciente del conflicto. Revista Economía Colombiana, 322. 
Jessop, B. (1999). Crisis del Estado de bienestar: hacia una nueva teoría del Estado y sus consecuencias sociales. Bogotá: Siglo del Hombre Editores, Universidad Nacional de Colombia.

Jiménez, J. y Ruiz, J. (2009). Política fiscal y equidad: una mirada comparada entre Europa y América Latina. Conferencia "Las políticas públicas ante la crisis global”. El Salvador, 31 agosto- $1^{\circ}$ de septiembre de 2009.

Junguito R. y Rincón, H. (2004). La política fiscal en el siglo XX en Colombia. Bogotá: Banco de la República.

Krugman, P. (2004). De vuelta a la economía de la gran depresión. Bogotá: Grupo Editorial Norma.

Lautier, B. (2005). En O. Rodríguez (Comp.) Una protección social mutualista y universal: condición para la eficacia de la lucha contra la pobreza. Sistemas de protección social: entre la volatilidad económica y la vulnerabilidad social (pp. 95-134). Bogotá: Universidad Nacional de Colombia.

Ocampo, J. y Malagón. J. (2012). Los efectos distributivos de la política fiscal en América Latina. Revista Pensamiento Iberoamericano, 10.

Ministerio de Hacienda y Crédito Público (2010a). Regla fiscal para Colombia. Bogotá: Comité Técnico Interinstitucional.

Ministerio de Hacienda y Crédito Público (2010b). Proyecto de Acto Legislativo por el cual se establece el derecho a la sostenibilidad fiscal para alcanzar los fines del Estado Social de Derecho. Exposición de Motivos. Bogotá: Ministerio de Hacienda y Crédito Público.

Misas, G. (2002). La ruptura de los 9o. Del gradualismo al colapso. Bogotá: Universidad Nacional de Colombia.

Moller, L. (2012). Política fiscal en Colombia: aprovechamiento de su potencial para lograr una sociedad más equitativa. Bogotá: Banco Mundial, Documento de Trabajo n. ${ }^{\circ} 67623$.

Neffa, J. (1998). Modos de regulación, regímenes de acumulación y sus crisis en Argentina (1880-1996). Una contribución a su estudio desde la teoría de la regulación. Buenos Aires: Asociación Trabajo y Sociedad.

O’ connor, J. (1994). La crisis fiscal del Estado. Barcelona: Ediciones Península.

Panitch, L. (2000). El nuevo Estado Imperial. New Left Review, 11(1), 5-20.

Perfetti, J. (2010). Ciencia, tecnología e innovación (CT+I). En R. Steiner y V. Traverso (Eds). Colombia 2010-2014: propuestas de política pública (pp. 321-374). Bogotá: Fedesarrollo, CAF. 
Perry, G. (2010). Hacia una reforma tributaria estructural. En R. Steiner y V. Traverso (Eds). Colombia 2010-2014: propuestas de política pública (pp. 13-65). Bogotá: Fedesarrollo, CAF.

Perry, G. y Herrera, A. (1994). Finanzas públicas, estabilización y reforma estructural en América Latina. Washington: Banco Interamericano de Desarrollo.

Rodríguez, O. (2007). Las transferencias: entre el sistema de protección social, la gobernabilidad macro y la construcción territorial del Estado. En: Bien-estar y macroeconomía 2007. Más allá de la retórica. Bogotá: Universidad Nacional de Colombia.

Servén, L. (2008). Fiscal redistribution and income inequality in Latin America. Washington: The World Bank Development Research Group.

Theret, B. (2000). Nueva economía institucional, economía de las convenciones y teoría de la regulación: ¿hacia una síntesis institucionalista? Noticias de la Regulación, $35,1-5$.

Zibechi, R. (2010). América Latina: contrainsurgencia y pobreza. Bogotá: Ediciones Desde Abajo. 
